\title{
Mineralogy of V-type asteroids as a constraining tool of their past history
}

\author{
S.F.A. Batista ${ }^{a, b, c, *, 1}$, T.M. Seixas ${ }^{a, c}$, M.A. Salgueiro da Silva ${ }^{a, c}$, R.M.G. de Albuquerque ${ }^{a}$ \\ ${ }^{a}$ Departamento de Física e Astronomia da Faculdade de Ciências da Universidade do Porto, Rua do Campo Alegre, 687, 4169-007 Porto, Portugal \\ ${ }^{\mathrm{b}}$ Centro de Astrofísica da Universidade do Porto, Rua das Estrelas, 4150-762 Porto, Portugal

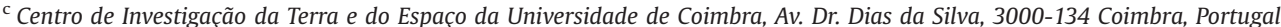

\section{A R T I C L E I N F O}

Article history:

Received 17 April 2014

Received in revised form

22 October 2014

Accepted 23 October 2014

Available online 4 November 2014

Keywords:

Vesta

Vestoids

HED meteorites

Mineralogy

Parent bodies

\begin{abstract}
A B S T R A C T
In the past few years, the genetic relationship between (4) Vesta, Vestoids and HED meteorites was reinforced (Drake, 2001, Meteorit. Planet. Sci. 36 (4), 501-513). It is believed that Vestoids and HED meteorites were originated from a collision suffered by (4) Vesta, during the early stages of the Solar System. Due to the effects of dynamical resonances, several fragments of this collision were ejected into near-Earth orbits and some of them have originated the so-called HED meteorites. We aim to infer about the hypothetical collision suffered by (4) Vesta and its connection to the genetic relationship between V-type asteroids and HED meteorites. For this purpose, reflectance spectra of a set of $11 \mathrm{~V}$-type asteroids and 55 HED meteorites were obtained, respectively, from the publically available MIT-UH-IRTF Joint Campaign for NEO Reconaissance and RELAB database.

Initially, for each of the selected V-type asteroids, we attempted to identify its meteoritic analogue. Afterwards, we have performed a numerical spectral analysis based on the Hapke radiative transfer model. We report the inferred surface composition and mineralogy of the V-type asteroids, for which we have identified a meteoritic analogue.

Our results strength the relationship between HED meteorites and V-type asteroids, as also suggested by the results from the Dawn mission (de Sanctis et al., 2012, Science, 336 (6082), 697-690; 2013 Meteorit. Planet. Sci. 48 (11) 2166-2184; McSween et al., 2011, Space Sci. Rev. 163 (1-4), 141-174; 2013, Meteorit. Planet. Sci. 48 (11) 2090-2104). The latter is contradicting the results from Schiller et al. (2011, Astrophys. J. 740 L22) and Wasson (2013, Earth Planet. Sci. Lett. 381 138-146), which questioned this linkage. We also report the best meteoritic kind for the studied V-type asteroids, by comparing their spectra and mineralogies. We also report the pyroxenes mineralogical distributions of the HED meteorites, inferred through the Hapke radiative transfer model, which can be suitable for comparison with future mineralogical studies of these objects.
\end{abstract}

(c) 2014 Elsevier Ltd. All rights reserved.

\section{Introduction}

Establishing possible linkages between asteroids and meteorites is of crucial importance as they allow us to understand the compositional and thermal gradients in the solar nebula. A topic of interest is the history of very early nebular solids, which provide important constraints on nebular conditions and processes fundamental to astrophysical models of nebular evolution. A discussion

\footnotetext{
* Corresponding author.

E-mail addresses: s.f.assuncaobatista-1@tudelft.nl (S.F.A. Batista), tmseixas@fc.up.pt (T.M. Seixas).

${ }^{1}$ Current address: Faculty of Aerospace Engineering, Technical University Delft,
} Kluyverweg 1, 2629 HS Delft, The Netherlands. about possible parent bodies across the diversity of meteorites is provided by Burbine et al. (2002).

(4) Vesta is quoted to be a surviving differentiated protoplanet (Russell et al. 2012). According to spectral data, orbital dynamics studies and remote sensing data from the DAWN mission, the genetic relationship between HED meteorites and (4) Vesta has been reinforced during the last few years (McCord et al., 1970; Binzel and Xu, 1993; Binzel et al., 1997; Drake, 2001; de Sanctis et al. 2012, 2013; McSween et al. 2011, 2013). But, this linkage was early questioned (Wasson and Wetherill, 1979). Indeed, recently there are some authors still questioning this linkage (see, e.g., Schiller et al., 2011; Wasson, 2013). In one hand, Schiller et al. (2011) discuss that the ${ }^{26} \mathrm{Mg}^{*}$ variations in eucrites and diogenites imply that near complete solidification of the HED parent body occurred in a short timescale of 2-3 Myr. According to thermal 
models, the latter rapid cooling and magma ocean crystallization could only take place in small asteroids with a dimension inferior to $100 \mathrm{~km}$. On the other hand, Wasson (2013) argue that spectral similarities between (4) Vesta and HED meteorites are not enough to establish a genetic linkage between both. Wasson (2013) also argues that more than half of the $\mathrm{V}$-type asteroids do not belong to the so-called Vesta dynamical family. Wasson (2013) concludes that HED are not from Vesta, but may come from the same parent body as pallasites and IIIAB irons.

The surface of (4) Vesta exhibits strong absorption features near 0.9 and $1.9 \mu \mathrm{m}$, evidencing the presence of Fe-bearing pyroxenes. Data obtained with the Dawn VIR instrument revealed, however, large variations in pyroxenes mineralogies (de Sanctis et al., 2012, 2013). The VIR spectra is consistent with a surface mineralogy similar to howardites (de Sanctis et al., 2012, 2013), confirming the evidence pointed out by Hiroi et al. (1995). Nevertheless, the regolith of (4) Vesta also contains varying proportions of eucritic and diogenitic materials, at different locations (de Sanctis et al., 2013). Olivine was also detected in the Nothern hemisphere of (4) Vesta (Ammannito et al., 2013). The giant impact suffered by (4) Vesta, which formed the Rheasilvia basin, excavated a large amount of eucritic and diogenitic material (Takeda 1997) and redistributed it over the surface. The mineralogical composition of the deepest layers of the basin are dominated by orthopyroxene-rich materials (de Sanctis et al. 2013).

(4) Vesta is close to the 3:1 jovian and $v_{6}$ resonances, which may be a powerful mechanism responsible for the ejection of V-type asteroids into near-Earth orbits (also called as Near Earth Asteroids or NEA) and for the delivery of HED meteorites. Currently, there are some known V-type asteroids residing in near-Earth orbits, such as the following examples: (3908) Nyx, (4055) Magellan, (5604) 1992 FE or (6613) 1993 VW.

We aim to infer the mineralogical compositions of HED meteorites and of some $\mathrm{V}$-type asteroids using the Hapke radiative transfer model. It is also foreseen to test the genetic linkages between V-type asteroids and HED meteorites, which was recently questioned by some authors (Schiller et al., 2011; Wasson, 2013). The paper is organized as follows: in Section 2, we describe the application of adapted Hapke's bidirectional reflectance model to the spectral deconvolution of the selected asteroids and meteorites; in Section 3, we justify the model parameterization and provide a basic description of the data selected; in Section 4, we discuss the performance of the described model on laboratorial samples, HED meteorites and V-type asteroids, we report an analysis of their mineralogies and we discuss the genetic relationship between V-type asteroids and HED meteorites; in Section 5, we stress out the outlines of this paper.

\section{Model description}

According to Hapke's radiative transfer model (Hapke, 1993), the bidirectional radiance coefficient (defined as the ratio of bidirectional reflectance of a surface to that of a Lambertian surface with no preferential escape of singly scattered light) of a semi-infinite medium of regolith particles whose size is larger than the wavelength $\lambda$, is given by:

$r_{H}(e, i, g)=\frac{w}{4\left(\mu+\mu_{0}\right)}\left[\left[1+B_{S}(g)\right] p(g)+H\left(x=\mu_{0}, w\right) H(x=\mu, w)-1\right]$

where $i, e$ and $g$ are the incidence, emergence, and phase angles, respectively, and $\mu_{0}=\cos (i), \mu=\cos (e)$. In addition, $w$ represents the average particle single scattering albedo, $B_{S}(g)$ represents the opposition effect, $p(g)$ is the average single-particle phase function, and $H(x, w)$ is the Ambartsumian-Chandrasekhar scattering function for isotropic particles. According to Mustard and Pieters (1989), $B_{S}(g)$ can be neglected for phase angles greater than $15^{\circ}$. All spectral data selected from the RELAB database satisfy this condition. The single-particle phase function is given by a two-term Legendre polynomial of the form:

$p(g)=1+b \cos (g)+c\left(1.5 \cos ^{2}(g)-0.5\right)$

where $b$ describes the angular width of the scattering lobes and $c$ describes the amplitude of the backscattered lobe relative to the forward scattered lobe. Appropriate average values for $b$ and $c$ were taken from Mustard and Pieters (1989) and Lucey (1998).

The Ambartsumian-Chandrasekhar function $H(x)$ is given, in very good approximation, by (Hapke, 1993):

$H(x)=\left[1-[1-\sqrt{1-w}] x\left[r_{0}+\left(1-\frac{1}{2} r_{0}-r_{0} x\right) \ln \left(\frac{1+x}{x}\right)\right]\right]^{-1}$

where

$r_{0}=(2 / 1+\sqrt{1-w})-1$

Albedo spectra $w(\lambda)$ of minerals can be obtained from their reflectance spectra by iterative inversion of Eq. (1), provided that the corresponding phase functions are specified. Asteroid regolith's and powder mineral or meteorite analogue samples can be described as intimate mixtures of minerals for which, according to Hapke mixing model (Hapke, 1993), the average albedo $\left(w_{\text {mix }}\right)$ is a linear combination of the albedos $\left(w_{i} ; i=1, \ldots, n_{m}\right)$ of the component minerals weighted by corresponding relative cross-sections $\left(x_{i}\right)$ :

$w_{\text {mix }}=\sum_{i=1}^{n_{m}} x_{i} w_{i}$

The phase function of an intimate mixture is an average of the phase functions $\left(p_{i}\right)$ of component minerals weighted by the products of their relative cross-sections and albedos:

$p_{\text {mix }}=\frac{\sum_{i=1}^{n_{m}} x_{i} w_{i} p_{i}}{\sum_{i=1}^{n_{m}} x_{i} w_{i}}$

It turns out from Eq. (5) that the wavelength dependence of albedos $w_{i}(\lambda)$ gives rise to a wavelength dependent average phase function $p_{\text {mix }}(\lambda)$, even if the phase functions $p_{i}(g)$ are independent of wavelength. This last assumption is valid only as an approximation, since, in general, phase functions depend on refraction index which is a function of wavelength. This means that assuming wavelength-independent phase functions for component minerals can lead to distortions in the determination of their albedos $w_{i}(\lambda)$. It is also known that space weathering effects have a redning effect on asteroid albedos that cannot be reproduced by albedos of intimate mixtures of pristine minerals. To account for these unavoidable modeling deficiencies, we consider an additional wavelength-dependent contribution $U(\lambda)$ to $w_{\text {mix }}(\lambda)$ :

$w_{\text {mix }}=\sum_{i=1}^{n_{m}} x_{i} w_{i}+U(\lambda)$

We assume that $U(\lambda)$ is a smooth function that can be represented by a low order polynomial:

$U(\lambda)=\sum_{k=0}^{n} A_{k} \lambda^{k}$

where $A_{k}$ are constant values to be fitted. This term can also model the presence of optically neutral phases not considered in the mixture. We have considered a third degree polynomial $(n=3)$ in our calculations. The model radiance coefficient of a mixture of previously selected minerals, $r_{\text {mix }}$, is fitted to real spectra through a nonlinear least-squares minimization that takes as parameters mineral relative cross-sections $\left(x_{i}\right)$ and the polynomial coefficients of function $U(\lambda)$. The goodness-of-fit is specified by the standard 
deviation $\sigma_{f}=\sqrt{S /(N-p)}$, where $S$ is sum of the squares of the fit residuals, $N$ is the number of points of the fitted spectrum and $p=n_{m}+3$ is the number of fitting parameters. The calculations were implemented in Microsoft Excel, using the generalized reduced gradient (GRG) nonlinear minimization method available in the Solver add-in. The relative cross-sections $x_{i}$ were subject to the following constraints: $x_{i} \geq 0$ and $\sum_{i=1}^{n_{m}} x_{i}=1$. Mass fractions $\left(M_{i}\right)$ of component minerals are then determined through the relation:

$M_{i}=\frac{\rho_{i} d_{i} x_{i}}{\sum_{k=1}^{n_{m}} \rho_{k} d_{k} x_{k}}$

where $\rho_{i}$ and $d_{i}$ are, respectively, the particle density and grain size of each component mineral.

The reflectance spectra of asteroids, as measured, is often uncalibrated and normalized to unit at a given wavelength. Therefore, we adopted the usual calibration procedure by using the known value of the respective geometric albedo, which is expected to match the reflectance at $\lambda=0.55 \mu \mathrm{m}$, to unnormalize the reflectance. To derive the uncertainties in the inferred mineralogies of the asteroids, we have followed the procedure adopted by Clark et al. (2006).

\section{Asteroid, meteorite and mineral selection}

For the purpose of this study, we selected a set of $11 \mathrm{~V}$-type asteroids from the "The MIT-UH-IRTF Joint Campaign for NEO Spectral Reconnaissance" (Rayner et al., 2003), available online at http://smass.mit.edu/minus.html. This is an ongoing joint observing program for routine measurement of Near Earth Objects (NEO) spectra, conducted by MIT, University of Hawaii and the NASA Infrared Telescope Facility (IRTF). A low-to-medium resolution NIR spectrograph and imager called SpeX, is used to obtain 0.8 to $2.5 \mu \mathrm{m}$ spectra of NEOs. When available, visible wavelength data from SMASS survey are also included. Spectra are normalized at $0.55 \mu \mathrm{m}$, when visible wavelength data are available; otherwise, normalization is made near $1.21 \mu \mathrm{m}$. The selected set of V-type asteroids is listed in Table 1.

On the other hand, we have selected a set of 55 HED meteorites from the RELAB database (Reflectance Experiment Laboratory) (Pieters and Hiroi, 2004), available at http://www.planetary. brown.edu/relab). The laboratorial spectra were obtained in the range between 0.3 and $2.6 \mu \mathrm{m}$, with a sampling resolution of $0.005 \mu \mathrm{m}$. The RELAB instrument is designed to simulate the diverse viewing geometries in remote telescopic measurements. A $30^{\circ}$ incident angle and a $0^{\circ}$ emission angle (measured from the vertical) were the default parameters for the measured spectra. Further details about the RELAB database and of how the reflectance spectra were obtained are available in the RELAB user's manual. The selected set of HED meteorites is listed in Table 2.

It has long been known that the reflectance spectra of the so-called Vestoids are similar to that of (4) Vesta (McCord et al., 1970). The reflectance spectra of V-type asteroids in the visible and NIR are similar to the reflectance spectra of basaltic achondrite HED meteorites (e.g., Burbine et al., 2002). Their reflectance spectra show clearly the presence of two distinct absorption features, located at around $\sim 0.9$ and $\sim 1.9 \mu \mathrm{m}$, which are indicative of the presence of pyroxene and possibly olivine minerals. In addition, the visible region of the V-type asteroids reflectance spectra shows a strong UV absorption edge also found among the HED meteorites reflectance spectra. In some cases, another observable feature is a spectral slope between 1.1 and $1.5 \mu \mathrm{m}$, which can be indicative of the presence of neutral phases, NiFe metal content and olivine abundance.
Table 1

List of the 11 selected V-type asteroids and related data. It is provided the type (according to the Tholen classification), some orbital elements (such as, the semimajor axis $a$, the eccentricity $\varepsilon$ and the orbital period) and some physical elements (such as the diameter of the asteroids, the geometric albedo and the absolute magnitude) for each asteroid. Almost all of the data were obtained from the JPL Small-Body Database, provided by NASA, available at http://ssd.jpl.nasa.gov/sbdb. cgi\#top.

\begin{tabular}{lllll}
\hline Asteroid name & $\boldsymbol{a}(\mathbf{A U})$ & $\boldsymbol{e}$ & Diameter $(\mathbf{k m})$ & Geometric albedo \\
\hline (4) Vesta & 2.362 & 0.089 & 530.00 & 0.4228 \\
(854) Frostia & 2.369 & 0.174 & $7.84^{2}$ & $0.4154^{2}$ \\
(3908) Nyx & 1.927 & 0.459 & 1.00 & 0.2300 \\
(4055) Magellan & 1.820 & 0.326 & 2.49 & 0.3100 \\
(5604) 1992 FE & 0.927 & 0.405 & 0.55 & 0.4800 \\
(6611) 1993 VW & 1,696 & 0.484 & 1.20 & $0.3000^{1}$ \\
(21238) Panarea & 2.542 & 0.107 & $5.22^{2}$ & $0.3729^{2}$ \\
(52750) 1998 KK17 & 1.427 & 0.525 & $1.06^{2}$ & $0.3930^{2}$ \\
(137924) 2000 BD19 & 0.876 & 0.895 & $0.97^{2}$ & $0.2470^{2}$ \\
(286458) 2005 VW & 2.775 & 0.032 & - & - \\
2003 FT3 & 2.673 & 0.572 & - & - \\
\hline
\end{tabular}

Notes: Data obtained from: ${ }^{1}$ Binzel et al. (2001); ${ }^{2} \mathrm{MP}^{3} \mathrm{C}$ : Minor Planet Physical Properties Catalogue (available online at http://mp3c.oca.eu/MP3C/).

Pyroxenes spectra show two distinctive absorption features, located at around 1 - and 2- $\mu \mathrm{m}$ (Burns, 1993), due to electronic transitions of $\mathrm{Fe}^{2+}$ ions in the M2 crystallographic site (Burns, 1970). According to mineral chemistry, the band centers of these two absorption features can occur at different wavelengths (Cloutis and Gaffey, 1992). Additional features near $1.2 \mu \mathrm{m}$ can be originated by the presence of $\mathrm{Fe}^{2+}$ ions in the M1 site (Klima et al., 2007).

Olivines show a complex absorption at $\sim 1 \mu \mathrm{m}$ (Nelson et al., 1993) due to electronic transitions of $\mathrm{Fe}^{2+}$ in the olivine crystallographic site (Burns, 1970). This absorption feature can move towards higher wavelengths as the $\mathrm{Fe}^{2+}$ content increases. On the other hand, the reflectance spectrum of plagioclase shows a weak absorption peak at $\sim 1.25 \mu \mathrm{m}$, which may be difficult to detect (Nelson et al., 1993).

Neutral phases are usually chosen to account for inappropriate end-member grain sizes. These minerals do not show any absorption feature as a function of the wavelength (Nelson et al., 1993). Usually, their presence is identified by an overall lowering of the albedo or by the presence of a spectral slope (Nelson et al., 1993). Actually, inferring about which opaque minerals may be present in a certain reflectance spectrum is an arduous task to accomplish. These effects can be modeled, at least partially, with the inclusion of the $U(\lambda)$ function, which may be viewed, in this context, also as an albedo background curve.

To model the mineralogies of the asteroids and meteorites considered for this study, we selected a set of reasonable endmember minerals, with appropriate grain sizes, from the RELAB database (Pieters and Hiroi, 2004). This selection took into account the possible mineralogy pointed out above for the selected V-type asteroids and HED meteorites. Hence, several types of pyroxenes, two types of olivines and plagioclases and some opaque minerals were selected (see list in Table 3).

\section{Discussion}

\subsection{Model performance on laboratorial mixtures}

To evaluate the performance of the model described in Section 2, we have first tested it in laboratorial mixtures of orthopyroxenes (Opx) and clinopyroxenes (Cpx) previously studied by Sunshine et al. (1990) and whose spectra are available in the RELAB database (Pieters and Hiroi, 2004). The samples have two distinct grain 
Table 2

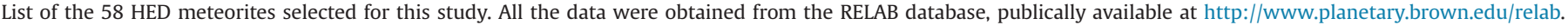

\begin{tabular}{|c|c|c|c|c|c|}
\hline \multirow[t]{2}{*}{ Relab file } & \multirow[t]{2}{*}{ Sample ID } & \multirow[t]{2}{*}{ Sample name } & \multirow[t]{2}{*}{ Meteorite type } & \multicolumn{2}{|c|}{ Grain size proportion } \\
\hline & & & & Min. size & Max. size \\
\hline CAMP71 & MP-TXH-071-A & ALHA77256,143 & Diogenite & 0 & 25 \\
\hline CAMP77 & MP-TXH-077-A & LAP91900,27 & Diogenite & 0 & 25 \\
\hline CAMP95 & MP-TXH-095-A & A-881526,90 & Diogenite & 0 & 25 \\
\hline CAMP81 & MP-TXH-081-A & Aioun el Atrouss & Diogenite & 0 & 25 \\
\hline CAMP88 & MP-TXH-088-A & Tatahouine & Diogenite & 0 & 25 \\
\hline CAMP68 & MP-TXH-068-A & GR095555,22 & Diogenite & 0 & 25 \\
\hline CBMB74 & MB-TXH-074-A & Y-75032,HR & Diogenite & 0 & 25 \\
\hline CBMB73 & MB-TXH-073-A & Y-74013,HR & Diogenite & 0 & 25 \\
\hline CBMB95 & MB-TXH-095-B & Johnstown & Diogenite & 25 & 45 \\
\hline CDMB67 & MB-TXH-067-D & EETA79002,146 & Diogenite & 75 & 125 \\
\hline CAMP84 & MP-TXH-084-A & Cachari & Eucrite & 0 & 25 \\
\hline CAMP86 & MP-TXH-086-A & Moore County & Eucrite & 0 & 25 \\
\hline CAMB97 & MB-TXH-097-A & Stannern & Eucrite & 0 & 25 \\
\hline CAMP87 & MP-TXH-087-A & Pasamonte & Eucrite & 0 & 25 \\
\hline CBMB69 & MB-ТХH-069-В & Millbillillie $25-45 \mu \mathrm{m}$ & Eucrite & 25 & 45 \\
\hline CDMB96 & MB-TXH-096-D & Padvarninkai & Eucrite & 25 & 45 \\
\hline CCMB71 & MB-TXH-071-C & Y-74450,92 & Eucrite & 45 & 75 \\
\hline CCMB72 & MB-TXH-072-C & ALH-78132,61 & Eucrite & 45 & 75 \\
\hline CDMB70 & MB-TXH-070-D & Juvinas & Eucrite & 75 & 125 \\
\hline CDMB66 & MB-TXH-066-D & ALHA76005,85 & Eucrite & 75 & 125 \\
\hline CDMB99 & MB-TXH-099-D & ALH85001,29 <25 $<\mathrm{m}$ (dry-sieved) & Eucrite & 0 & 25 \\
\hline CAMP89 & MP-TXH-089-A & Bereba & Eucrite & 0 & 25 \\
\hline CAMP90 & MP-TXH-090-A & Bouvante & Eucrite & 0 & 25 \\
\hline CAMP91 & MP-TXH-091-A & Jonzac & Eucrite & 0 & 25 \\
\hline CAMP92 & MP-TXH-092-A & Serra de Mage & Eucrite & 0 & 25 \\
\hline C1MT28 & MT-HYM-028 & MAC02522,7 eucrite & Eucrite & 0 & 45 \\
\hline C1MT29 & MT-HYM-029 & EET87520,23 eucrite & Eucrite & 0 & 45 \\
\hline С1MT30 & MT-HYM-030 & ALHA81001,43 eucrite & Eucrite & 0 & 45 \\
\hline С1MT31 & MT-HYM-031 & PCA91078,16 eucrite & Eucrite & 0 & 45 \\
\hline C1MT32 & MT-HYM-032 & BTN00300,21 eucrite & Eucrite & 0 & 45 \\
\hline C1MT33 & MT-HYM-033 & MET01081,12 eucrite & Eucrite & 0 & 45 \\
\hline CAMP96 & MP-TXH-096-А & A-881819,110 & Eucrite & 0 & 25 \\
\hline CAMP75 & MP-TXH-075-A & EET87542,25 & Eucrite & 0 & 25 \\
\hline C1MP118 & MP-TXH-118 & EET92003,15 (eucrite) < $125 \mu \mathrm{m}$ & Eucrite & 0 & 125 \\
\hline C1MP119 & МР-ТХН-119 & PCA91006,18 (eucrite) $<125 \mu \mathrm{m}$ & Eucrite & 0 & 125 \\
\hline CAMP94 & MP-TXH-094-A & A-87272,96 & Eucrite & 0 & 25 \\
\hline CAMP72 & MP-TXH-072-A & EETA79005,99 & Eucrite & 0 & 25 \\
\hline CAMP78 & MP-TXH-078-A & LEW85303,98 & Eucrite & 0 & 25 \\
\hline C1MP121 & MP-TXH-121 & ALHA81001,41 (eucrite) $<125 \mu \mathrm{m}$ & Eucrite & 0 & 125 \\
\hline CAMP54 & MP-TXH-054-A & Ibitira $<25 \mu \mathrm{m}$ & Eucrite & 0 & 25 \\
\hline CAMP73 & MP-TXH-073-A & EET83376,12 & Howardite & 0 & 25 \\
\hline CAMP98 & MP-TXH-098-A & Y-790727,144 & Howardite & 0 & 25 \\
\hline CAMP99 & MP-ТХH-099-A & Y-791573,145 & Howardite & 0 & 25 \\
\hline C1MP125 & MP-TXH-125 & GR095574,9 (howardite) $<125 \mu \mathrm{m}$ & Howardite & 0 & 125 \\
\hline C1MP126 & MP-TXH-126 & QUE97001,28 (howardite) $<125 \mu \mathrm{m}$ & Howardite & 0 & 125 \\
\hline C1TB127 & TB-TJM-127 & Bialystok & Howardite & 0 & 150 \\
\hline CAMP70 & MP-TXH-070-A & Petersburg & Howardite & 0 & 25 \\
\hline CAMP97 & MP-TXH-097-A & Y-7308,142 & Howardite & 0 & 25 \\
\hline CAMP67 & MP-TXH-067-A & GR095535,12 & Howardite & 0 & 25 \\
\hline CAMP82 & MP-TXH-082-A & Binda & Howardite & 0 & 25 \\
\hline CAMP83 & MP-TXH-083-A & Bununu & Howardite & 0 & 25 \\
\hline CAMP85 & MP-TXH-085-A & Frankfort howardite & Howardite & 0 & 25 \\
\hline CAMP93 & MP-TXH-093-A & Le Teilleul & Howardite & 0 & 25 \\
\hline CAMP53 & MP-TXH-053-A & Kapoeta & Howardite & 0 & 25 \\
\hline CAMP69 & MP-TXH-069-A & QUE94200,19 & Howardite & 0 & 25 \\
\hline CDMB68 & MB-TXH-068-D & EET87503,97 75-125 $\mu \mathrm{m}$ & Howardite & 75 & 125 \\
\hline
\end{tabular}

sizes: small $(<45 \mu \mathrm{m})$ and large $(70-145 \mu \mathrm{m})$. The chosen endmember minerals, with appropriated grain sizes, were also obtained from the RELAB database. One can observe that the mineralogies obtained for these Opx-Cpx samples, as listed in Table 4, agree with the ones of Sunshine et al. (1990) within a margin error of $5 \%$ for grain sizes $<45 \mu \mathrm{m}$ and $70-145 \mu \mathrm{m}$. A better agreement would be possible if the grain size $(70-125 \mu \mathrm{m})$ of the chosen end-member minerals matched the grain size of the analyzed mixtures, since it is known that spectral absorption features are strongly affected by grain size effects (see e.g. Hapke, 1993 and references therein). In general, absorption increases with grain size leading to more pronounced absorption peaks in reflectance spectra. Indeed, the RELAB database does not include any $\mathrm{Cpx}$ or Opx spectra corresponding to grain sizes larger than $125 \mu \mathrm{m}$ that could be used to avoid this problem.

\subsection{Model performance on HED meteorites}

We have initially analyzed the effect of grain size on the determination of the mineralogy of the same meteorite. For this purpose, we considered the following RELAB samples of the meteorite Y-74450 with different grain size ranges (GSR): MB-TXH-071-A (GSR: 0-25 $\mu \mathrm{m}$; sample A); MB-TXH-071-B (GSR: 25-45 $\mu \mathrm{m}$; sample B); 
Table 3

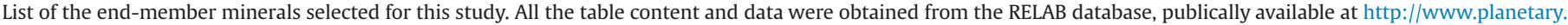
brown.edu/relab.

\begin{tabular}{|c|c|c|c|c|c|}
\hline \multirow[t]{2}{*}{ Relab file } & \multirow[t]{2}{*}{ Sample ID } & \multirow[t]{2}{*}{ Sample name (RELAB) } & \multirow[t]{2}{*}{ Mineral subtype (RELAB) } & \multicolumn{2}{|c|}{ Grain size proportion } \\
\hline & & & & Min. size & Max. size \\
\hline САРP37 & PP-TXH-037-A & Seven Sisters Is. & Plagioclase & 0 & 25 \\
\hline C1PP46 & PP-EAC-046 & PYX015 & Pyroxene Endiopside ${ }^{a}$ & 0 & 45 \\
\hline C1PP21 & PP-CMP-021 & Cpx 45 & Pyroxene clinopyroxene diopside & 0 & 45 \\
\hline CAPP38 & PP-TXH-038-A & St. Ludger-de-Milot hypersthene $<25 \mu \mathrm{m}$ & Hypersthene & 0 & 25 \\
\hline CAPA60 & PA-CMP-060-A & Split rock anorthite & Anorthite & 0 & 25 \\
\hline C1DL08A & DL-CMP-008-A & Wo 5 En 38 Fs $57($ E36-103, 100\% opx $)<45 \mu \mathrm{m}$ & Pyroxene clinopyroxene pigeonite & 0 & 45 \\
\hline C1AG10 & AG-TJM-010 & Augite & Pyroxene clinopyroxene augite & 0 & 45 \\
\hline C1DD98 & DD-MDD-098 & Fa 100 Fo $0<45 \mu \mathrm{m}$ & Olivine fayalite & 0 & 45 \\
\hline C1DD85P & DD-MDD-085-P & Fa 0 Fo $100<45 \mu \mathrm{m}$ pellet & Olivine forsterite & 0 & 45 \\
\hline CACR11 & CR-EAC-011 & CHR101 & Chromite & 0 & 45 \\
\hline C1PE30 & PE-CMP-030 & Web 45 & Enstatite & 0 & 45 \\
\hline CJB236 & JB-JLB-236 & NMNH-120414-1 & Pyroxene orthopyroxene bronzite & 0 & 45 \\
\hline CAEA09 & EA-EAC-009-A & TRO203A & Troilite & 0 & 45 \\
\hline СВРР37 & PР-TXH-037-B & Seven Sisters Is. & Plagioclase & 25 & 45 \\
\hline СВРР38 & PP-TXH-038-B & St. Ludger-de-Milot hypersthene $25-45 \mu \mathrm{m}$ & Hypersthene & 25 & 45 \\
\hline CBPA60 & PA-CMP-060-B & Split rock anorthite & Anorthite & 25 & 45 \\
\hline ССРР37 & PP-TXH-037-C & Seven Sisters Is. & Plagioclase & 45 & 75 \\
\hline C1PP01 & PP-EAC-001 & PYX005 & Pyroxene clinopyroxene Endiopside ${ }^{a}$ & 45 & 90 \\
\hline C1PP22 & PP-CMP-022 & Cpx 75 & Pyroxene clinopyroxene diopside & 45 & 75 \\
\hline ССРP38 & PP-TXH-038-C & St. Ludger-de-Milot hypersthene $45-75 \mu \mathrm{m}$ & Hypersthene & 45 & 75 \\
\hline C1PA60 & PA-CMP-060-C & Split Rock Anorthite & Anorthite & 45 & 75 \\
\hline C1LR180 & LR-CMP-180 & 70035,188 light-brown pyroxene B & Pyroxene clinopyroxene pigeonite & 0 & 125 \\
\hline C1P071 & PO-CMP-071 & St. Peter's fayalite & Olivine fayalite & 45 & 75 \\
\hline C1PO77 & PO-CMP-077 & Apache forsterite & Olivine forsterite & 45 & 75 \\
\hline C1PE31 & PE-CMP-031 & Web 75 & Enstatite & 45 & 75 \\
\hline C1PP52 & PP-EAC-052 & PYX119 & Pyroxene orthopyroxene bronzite & 45 & 90 \\
\hline C1MB06 & MB-CMP-006 & Mundrabilla troilite & Troilite & 0 & 250 \\
\hline C1SR70A & SR-JFM-070-A & BUR-5080 & Pyroxenoid wollastonite & 45 & 150 \\
\hline CDPP37 & PP-TXH-037-D & Seven Sisters Is. & Plagioclase & 75 & 125 \\
\hline C1PP23 & PP-CMP-023 & Cpx 125 & Pyroxene clinopyroxene diopside & 75 & 125 \\
\hline CDPP38 & PP-TXH-038-D & St. Ludger-de-Milot hypersthene $75-125 \mu \mathrm{m}$ & Hypersthene & 75 & 125 \\
\hline CDPA60 & PA-CMP-060-D & Split Rock Anorthite & Anorthite & 75 & 125 \\
\hline C1SR43A & SR-JFM-043-A & AZ-01 & Olivine forsterite & 45 & 150 \\
\hline C1PE32 & PE-CMP-032 & Web 125 & Enstatite & 75 & 125 \\
\hline C1LR78 & LR-CMP-178 & 70017,535 ilmenite & Ilmenite & 0 & 125 \\
\hline CASP16 & SP-EAC-016 & SPI116 & Spinel & 0 & 45 \\
\hline
\end{tabular}

a Endiopside is an obsolete term referring to magnesium-rich (or Mg-rich) augite. See Morimoto et al. (1989) for more details.

Table 4

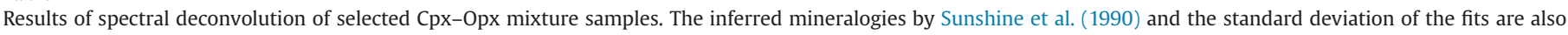

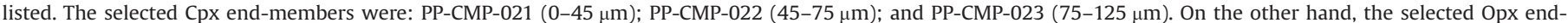
members were: PE-CMP-030 (0-45 $\mu \mathrm{m})$; PE-CMP-0031 (45-75 $\mu \mathrm{m})$; and PE-CMP-032 (75-125 $\mu \mathrm{m})$.

\begin{tabular}{|c|c|c|c|c|c|c|c|c|c|c|c|}
\hline \multirow[t]{2}{*}{ RELAB sample ID } & \multirow[t]{2}{*}{ RELAB file } & \multirow[t]{2}{*}{ Grain size $(\mu \mathrm{m})$} & \multicolumn{2}{|c|}{ This study } & \multicolumn{2}{|c|}{ Sunsine et al. (1990) } & \multirow[t]{2}{*}{$A_{0}$} & \multirow[t]{2}{*}{$A_{1}$} & \multirow[t]{2}{*}{$A_{2}$} & \multirow[t]{2}{*}{$A_{3}$} & \multirow[t]{2}{*}{$\sigma$} \\
\hline & & & Opx & Cpx & Opx & Cpx & & & & & \\
\hline XP-CMP-010 & C1XP10 & $0-45$ & 49 & 51 & 50 & 50 & 0.0361 & -0.0572 & 0.0331 & -0.0063 & $2.10^{-3}$ \\
\hline ХР-CMP-011 & C1XP11 & $0-45$ & 56 & 44 & 60 & 40 & 0.0305 & -0.0444 & 0.0252 & -0.0047 & $3.10^{-3}$ \\
\hline XP-CMP-012 & C1XP12 & $0-45$ & 37 & 63 & 40 & 60 & 0.0239 & -0.0437 & 0.0217 & -0.0034 & $1.10^{-3}$ \\
\hline XP-CMP-013 & C1XP13 & $0-45$ & 73 & 27 & 75 & 25 & 0.0313 & -0.0413 & 0.0204 & -0.0033 & $1.10^{-3}$ \\
\hline XP-CMP-014 & C1XP14 & $0-45$ & 20 & 80 & 25 & 75 & 0.0307 & -0.0576 & 0.0285 & -0.0046 & $2.10^{-3}$ \\
\hline XP-CMP-015 & C1XP15 & $0-45$ & 84 & 16 & 85 & 15 & 0.0358 & -0.0416 & 0.0239 & -0.0048 & $2.10^{-3}$ \\
\hline XP-CMP-016 & C1XP16 & $0-45$ & 17 & 83 & 15 & 85 & 0.0108 & -0.0104 & 0.0036 & -0.0006 & $1.10^{-3}$ \\
\hline XP-CMP-001 & С1XP01 & $70-145$ & 45 & 55 & 50 & 50 & -0.0255 & -0.0014 & 0.0024 & -0.0007 & $5.10^{-3}$ \\
\hline XP-CMP-002 & C1XP02 & $70-145$ & 52 & 48 & 60 & 40 & -0.0181 & -0.0112 & -0.0093 & 0.0042 & $7.10^{-3}$ \\
\hline XP-CMP-003 & С1XР03 & $70-145$ & 35 & 65 & 40 & 60 & -0.0348 & 0.0016 & -0.0009 & 0.0004 & $5.10^{-3}$ \\
\hline XP-CMP-004 & C1XP04 & $70-145$ & 74 & 26 & 75 & 25 & -0.0266 & -0.0142 & -0.0014 & 0.0016 & $4.10^{-3}$ \\
\hline XP-CMP-005 & C1XP05 & $70-145$ & 21 & 79 & 25 & 75 & 0.0091 & -0.1174 & 0.0713 & -0.0140 & $4.10^{-3}$ \\
\hline XP-CMP-006 & C1XP06 & $70-145$ & 83 & 17 & 85 & 15 & 0.0247 & -0.0505 & 0.0136 & -0.0006 & $4.10^{-3}$ \\
\hline XP-CMP-007 & С1XP07 & $70-145$ & 11 & 89 & 15 & 85 & -0.0646 & 0.0072 & -0.0180 & 0.0049 & $3.10^{-3}$ \\
\hline
\end{tabular}

MB-TXH-071-C (GSR: 45-75 $\mu \mathrm{m}$; sample C); and MB-TXH-071-D (GSR: 75-125 $\mu \mathrm{m}$; sample D).

One can see from Fig. 1 that, because of increasing bulk absorption, the reflectance of these samples is reduced globally with increasing grain size. The reduction in reflectance is more pronounced from $0-25 \mu \mathrm{m}$ to $25-45 \mu \mathrm{m}$ grain size ranges resulting in that spectral differences among samples B, C and D are significantly smaller than those between samples A and B. The inferred mineralogies for all Y-74450 samples are listed in Table 5 and the corresponding fits are shown in Fig. 2. Mineralogies of 
samples B, C and D deviate less than $5 \%$ from their average value, but this differs in 10-15\% from the mineralogy of sample A, with larger differences in Opx, Cpx and chromite abundances.

To deeper analyse the impact of uneven spectral changes induced by grain size variation, we list the detailed inferred mineralogical composition of samples A and B in Table 6. It is clear that the mixing model inferred for sample $A$, which has the largest reflectance, the presence of high reflectance minerals (wollastonite, forsterite and plagioclase) in detriment of diogenite, hypersthene, piogenite and chromite, which are enriched in the composition of sample B. In sample A, the abundances of the latter minerals appear to have been transferred partially to other minerals that have similar absorption features. In general, the transfer of abundance of one mineral to another one can occur without any significant fit improvement when their reflectance spectra show important similarities (e.g., spectral bands in the case of the pyroxenes). Despite the differences between the inferred abundances of Opx and Cpx for these four samples, it is important to stress out that the total pyroxene abundance $(\mathrm{Opx}+\mathrm{Cpx})$ is approximately equal in all of them: $65 \%$ in sample A; $66 \%$ in samples B and D; $68 \%$ in sample-C. It is likely that the spurious disparities in the inferred mineralogies of samples A-D are caused by grain size effects unaccounted for by the mixing model as, e.g., the intrinsic dependence of the phase function parameters $b$ and $c$ on grain size.

The mixing model was also applied to the HED meteorites listed in Table 2, to infer about their mineralogical compositions. We list the inferred mineralogies for all HED meteorites in Table 7. The goodness of the fits for the results listed in Table 7 ranges between $2.2 \times 10^{-3}$ (for the best fit) and $1.3 \times 10^{-2}$ (for the worst fit). In Fig. 3, we show

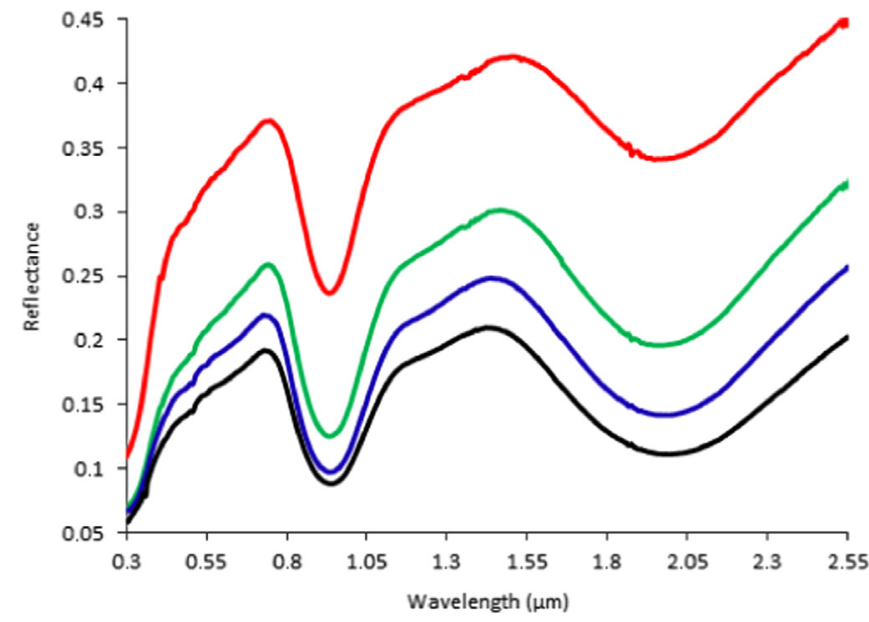

Legend:

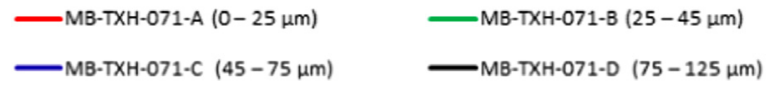

Fig. 1. Reflectance spectra of the samples MB-TXH-071-A, MB-TXH-071-B, MB-TXH-071-C and MB-TXH-071-D of meteorite Y-74450. the boxplots of the derived abundances of Opx and Cpx for the selected HED meteorites. The average mineralogical composition for the selected eucrites is $21 \pm 3 \%$ of orthopyroxenes, $40 \pm 4 \%$ of clinopyroxenes, $10 \pm 3 \%$ of olivine, $7 \pm 2 \%$ of chromite, $11 \pm 3 \%$ of troilite, $6 \pm 1 \%$ of spinel and $3 \pm 1 \%$ of plagioclase. On the other hand, the average mineralogical composition for the selected howardites is $47 \pm 7 \%$ of orthopyroxenes, $25 \pm 4 \%$ of clinopyroxenes, $8 \pm 3 \%$ of olivine, $5 \pm 2 \%$ of chromite, $7 \pm 3 \%$ of troilite and $6 \pm 1 \%$ of spinel. The average mineralogical composition of the ten diogenites samples is $73 \pm 10 \%$ of orthopyroxenes, $13 \pm 2 \%$ of clinopyroxenes, $5 \pm 1 \%$ of olivine, $5 \pm 2 \%$ of chromite, $2 \pm 2 \%$ of troilite and $2 \pm 1 \%$ of spinel.

Bowman et al. (1997) derived the average mineralogical composition for 21 diogenites and reported that these samples were composed by $92.2 \%$ of orthopyroxenes, $4.2 \%$ of olivine, $1.2 \%$ of clinopyroxenes, $0.9 \%$ of spinel, $0.4 \%$ of plagioclase, $0.1 \%$ of FeNi metal, $0.6 \%$ of troilite and $0.4 \%$ of silica phase. The average values that we derived for orthopyroxenes and clinopyroxenes do not seem to agree with the ones derived by Bowman et al. (1997), but our sample of diogenites represents just a subset of the sample used by Bowman et al. (1997). It is also possible that when, as in this case, fits involve a mineral mixture with more than two end-members, the uncertainty in the mineralogy determination may be larger than the uncertainty of $5 \%$ estimated for binary mixtures in Section 4.1. Despite the average values seem to disagree, we found that, on average, orthopyroxenes are clearly a major component of diogenites, as stressed out by Bowman et al. (1997). We have also detected the presence of olivine.

We have also compared some of our fitting results to the mineralogies inferred by other authors. Initially, we will consider the three following diogenitic samples: MP-TXH-068-A (GRO95555, henceforth GRO), MB-TXH-081-A (Aioun el Atrouss), and MB-TXH095-B (Johnstown). For each of these samples, we made ten fits with different initial conditions. We have noticed that the mixing model described in Section 2 is independent of the initial guessed modal composition and will converge, on average, to the same final solution. The results of corresponding best fit for each meteorite is shown in Fig. 4 and the inferred mineralogy is listed in Table 8. In all three cases, the background curve is nonmonotonic. Despite the fits are globally satisfactory, both qualitatively and quantitatively, they are clearly unable to fully reproduce a few spectral features. As examples, one can observe the misfit $1.3 \mu \mathrm{m}$ for GRO, or the observed misfit $0.6-0.8 \mu \mathrm{m}$ for Aioun el Atrouss. This misfit may be caused by different grain sizes of the meteorite samples and the assumed component minerals whose spectra were selected for spectral mixing.

We will also compare our individual results for these three diogenites with other studies in the literature. In this analysis, we will consider that our results are in good agreement with other authors if the differences are inferior than $5 \%$. Hereafter, we will discuss on the individual cases:

MP-TXH-068-A (GRO): Papike et al. (2000) inferred that GRO is composed by $96.7 \%$ of orthopyroxenes, $1.5 \%$ of spinel, $1.4 \%$ of silica phase and $0.2 \%$ of troilite and FeNi metal. We have found a lower orthopyroxene content (85\%) than Papike et al. (2000). We have also found the presence of clynopiroxenes, in contrast to the

Table 5

Inferred mineralogies for the samples of Y-74450 (see text for more details). The values are listed in units of vol\%.

\begin{tabular}{|c|c|c|c|c|c|c|c|c|}
\hline Sample & Opx & Cpx & Olivine & Anorthite & Chromite & Spinel & $\mathbf{O p x}+C_{p x}$ & $\sigma$ \\
\hline MB-TXH-071-A & 49 & 16 & 19 & 4 & - & 12 & 65 & $4.4 \times 10^{-3}$ \\
\hline MB-TXH-071-В & 31 & 35 & 15 & - & 10 & 9 & 66 & $5.8 \times 10^{-3}$ \\
\hline MB-TXH-071-C & 37 & 31 & 11 & - & 12 & 9 & 68 & $5.5 \times 10^{-3}$ \\
\hline MB-TXH-071-D & 40 & 26 & 11 & - & 15 & 8 & 66 & $4.7 \times 10^{-3}$ \\
\hline Average & 39 & 27 & 14 & 1 & 9 & 10 & 66 & - \\
\hline
\end{tabular}



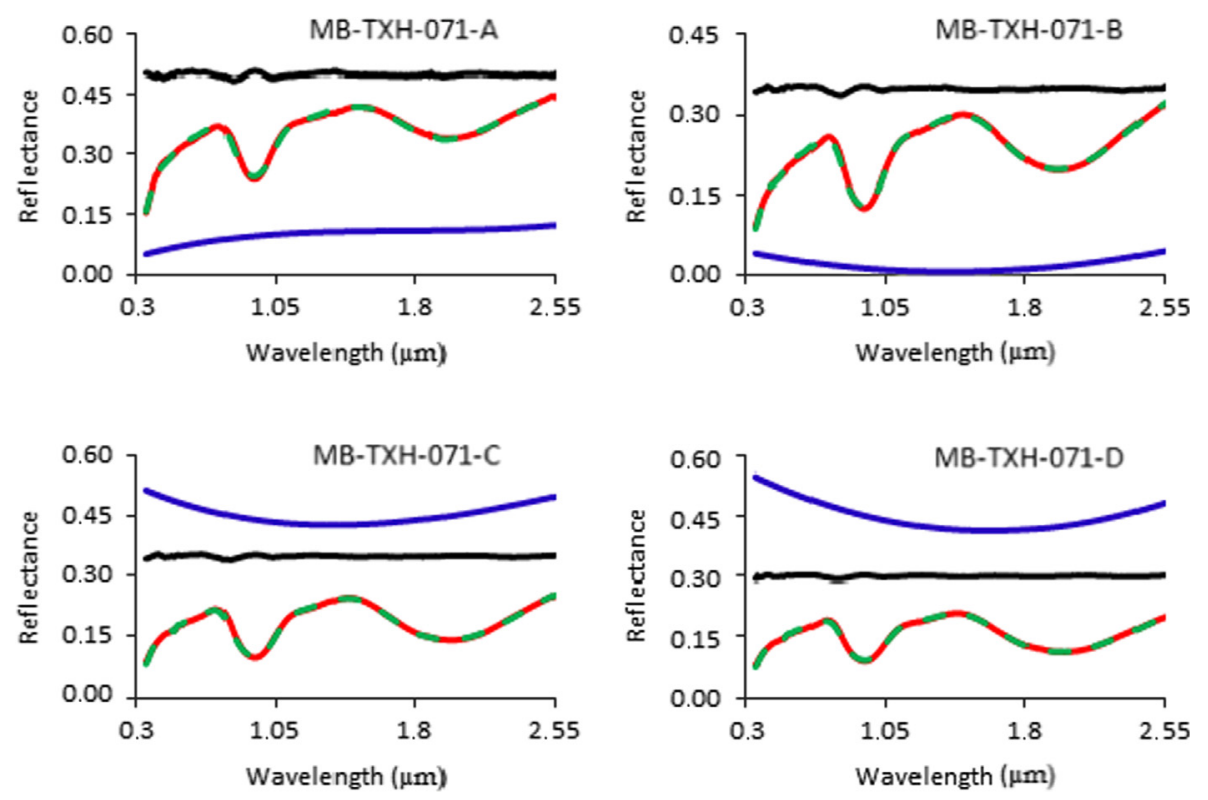

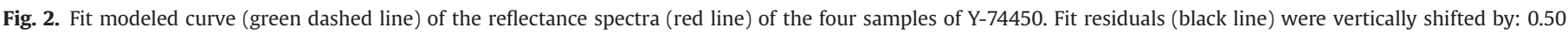

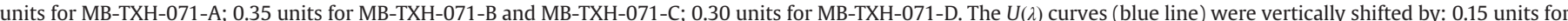

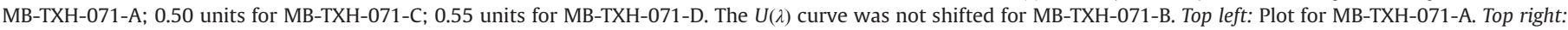

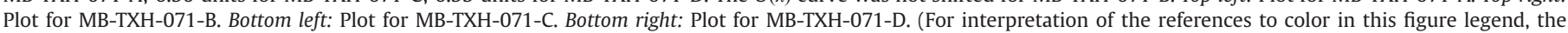
reader is referred to the web version of this article.)

Table 6

Detailed mineralogy inferred for samples MB-TXH-071-A and MB-TXH-071-B. The values are listed in units of vol\%.

\begin{tabular}{|c|c|c|c|c|c|c|c|c|c|c|c|c|}
\hline Sample ID & Plag & Dio & Hyper & Aug & Pio & Bron & Enst & Wolla & Fors & Faya & Chro & Spi \\
\hline MB-TXH-071-A & 4 & - & 12 & 8 & 13 & 10 & 4 & 18 & 9 & 11 & - & 12 \\
\hline MB-TXH-071-В & - & 12 & 35 & - & 19 & - & - & - & - & 15 & 10 & 9 \\
\hline
\end{tabular}

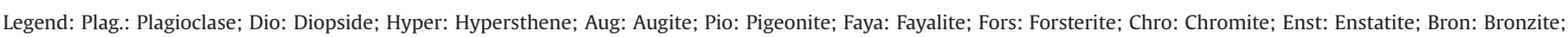
Wolla: Wollastonite; Spi: Spinel.

results of Papike et al. (2000). We have not found traces of neutral phases, which is in agreement with the low abundance of neutral phases found by Papike et al. (2000).

MP-TXH-081-A (Aioun el Atrouss): The inferred orthopyroxene (77\%) abundance is lower than the one found by Bowman et al. (1997) (98\%, on average). We have found the presence of clinopyroxenes and a higher average content of chromite than Bowman et al. (1997).

MB-TXH-095-B (Johnstown): Zema et al. (1997) inferred an average enstatite, ferrosilite and wollastonite content of $73.7 \%, 23.5 \%$ and $2.8 \%$, respectively. We have found a lower enstatite content for Johnstown than Zema et al. (1997) and Bowman et al. (1997). On the other hand, we have not found the presence of wollastonite. The latter is in agreement with Bowman et al. (1997), but opposing to the value reported by Zema et al. (1997). Bowman et al. (1997) found some traces of olivine on Johnstown, while we have found an olivine content of $10 \%$. We have not found traces of troilite, while Bowman et al. (1997) inferred a presence of $2 \%$. Donaldson and Sprague (2009) used a spectral deconvolution method to infer the following mineralogical composition for Johnstown: $66-76 \%$ of hypersthene; $21-31 \%$ of diopside; $5-15 \%$ of anorthite; $3-13 \%$ of olivine; and $0-10 \%$ of chromite. Our results are in good agreement with Donaldson and Sprague (2009). The average orthopyroxene content inferred here is around 50\%, being lower than the range presented by Donaldson and Sprague (2009). The inferred average clinopyroxenes abundance is higher than the range of Donaldson and Sprague (2009). On the other hand, the average olivine content is within the range given by Donaldson and Sprague (2009). We have not found, however, the presence of anorthite. Lawrence and Lucey (2007) have modeled the spectrum of Jonhstown using the Hapke radiative transfer model and have obtained the following modal mineralogy: 4.6\% of olivine; $91.0 \%$ of orthopyroxenes; $5.2 \%$ of clinopyroxenes; $3.6 \%$ of plagioclase feldspar; $2.9 \%$ of troilite; $3.8 \%$ of glass; and $3.4 \%$ of $\mathrm{Fe}-\mathrm{Ni}$ metal. Indeed, we have also inferred that orthopyroxenes have the highest modal content, but our value is lower than the one obtained by Lawrence and Lucey (2007). On the other hand, we have found a higher modal content of clinopyroxenes and a content of neutral phases higher than Lawrence and Lucey (2007) and no traces of olivine. Our modeled curve for the Johnstown meteorite (see Fig. 4) seems to better reproduce the experimental curve than the one presented by Lawrence and Lucey (2007).

We have also considered the average mineralogy listed in Table 5 for the polymict eucrite Y-74450, to compare against other studies. Lawrence and Lucey (2007) have performed a mixing spectral analysis of this meteorite and have inferred the following modal mineralogy: $4.6 \%$ of olivine, $30.5 \%$ of orthopyroxenes, $21.3 \%$ of clinopyroxenes, $36.0 \%$ of plagioclase, $1.2 \%$ of troilite and $2.1 \%$ of glass. On the other hand, Delaney et al. (1983) and Middlefehldt et al. (1998) have measured the following modal abundance for Y74450: $0.1 \%$ of olivine, $35.2 \%$ of orthopyroxene, $16.3 \%$ of clinopyroxene, $39.2 \%$ of feldspar, $0.7 \%$ of troilite and $4.8 \%$ of glass. Our inferred average abudance of orthopyroxenes is in good agreement with Delaney et al. (1983) and Middlefehldt et al. (1998), apart from a higher abundance of clinopyroxene and a lower abundance of plagioclase. Our results show, however, a higher abundance of neutral phases, such as chromite and spinel. The percentages of clinopyroxenes, orthopyroxenes and olivine are also in good agreement with Lawrence and Lucey (2007). However, our results evidence a much lower 
Table 7

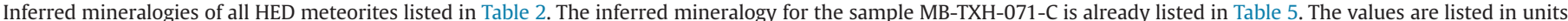
of vol\%.

\begin{tabular}{|c|c|c|c|c|c|c|c|c|c|c|c|c|c|c|c|c|c|c|}
\hline Sample ID & Plag & End & Dio & Hyper & Anor & Aug & Pio & Faya & Fors & Chro & Enst & Hed & Bron & Troi & Wolla & Ilm & Phos & Spi \\
\hline MP-TXH-071-A & - & - & - & - & - & - & 7 & 20 & - & - & 22 & - & 51 & - & - & - & - & - \\
\hline MP-TXH-077-A & - & - & - & - & - & - & 12 & - & - & 9 & 78 & - & - & - & - & - & - & - \\
\hline MP-TXH-095-А & - & - & - & 12 & - & - & 13 & 10 & - & - & 37 & - & 28 & - & - & - & - & - \\
\hline MP-TXH-081-A & - & - & - & - & - & - & 13 & - & - & 9 & 77 & - & - & - & - & - & - & - \\
\hline MP-TXH-088-A & - & - & - & - & - & - & 13 & - & - & 9 & 77 & - & - & - & - & - & - & - \\
\hline MP-TXH-068-A & - & - & - & - & - & - & 14 & 1 & - & - & 85 & - & - & - & - & - & - & - \\
\hline МB-ТХН-074-В & - & - & - & 6 & - & - & 21 & - & - & - & 54 & - & 14 & - & - & 3 & - & 2 \\
\hline MB-TXH-073-B & - & - & - & - & - & - & 7 & 12 & - & - & 27 & - & 54 & - & - & - & - & - \\
\hline MB-TXH-095-В & - & - & - & - & - & - & 15 & 5 & - & 3 & 72 & - & - & - & - & - & - & 5 \\
\hline MB-TXH-067-D & - & - & - & - & - & - & 15 & - & - & 15 & 38 & - & - & 21 & - & - & - & 11 \\
\hline MP-TXH-084-A & - & - & 9 & - & - & - & 26 & 20 & - & - & 31 & - & 5 & - & 10 & - & - & - \\
\hline MP-TXH-086-A & - & - & 19 & 2 & - & 2 & 28 & - & - & - & 47 & - & - & - & - & 1 & - & - \\
\hline MB-TXH-097-A & - & 3 & - & 7 & - & 5 & 17 & - & - & - & 9 & - & - & 50 & - & - & - & 9 \\
\hline MP-TXH-087-A & - & - & - & 35 & 5 & 15 & 19 & 4 & 4 & - & - & - & - & 10 & 2 & 1 & - & 5 \\
\hline МB-ТХН-069-В & - & - & - & - & - & 10 & 41 & - & 6 & 13 & 19 & - & - & - & - & - & - & 11 \\
\hline MB-TXH-096-D & - & - & - & - & - & 12 & 37 & - & - & 13 & 13 & - & - & 8 & - & - & - & 17 \\
\hline MB-TXH-072-C & - & - & - & - & - & - & 40 & - & - & 5 & 14 & - & - & 26 & - & - & - & 14 \\
\hline MB-TXH-070-D & - & - & - & - & - & - & 41 & - & - & 17 & 23 & - & - & - & - & - & - & 18 \\
\hline MB-TXH-066-D & - & - & - & - & - & 11 & 43 & - & - & 46 & - & - & - & - & - & - & - & - \\
\hline MB-TXH-099-D & - & - & - & - & - & - & 35 & - & - & 34 & 2 & - & - & 26 & - & - & - & 4 \\
\hline MP-TXH-089-A & - & - & - & - & - & - & 10 & - & 6 & 1 & 36 & - & - & 37 & - & - & - & 11 \\
\hline MP-TXH-090-А & 31 & 9 & - & 12 & - & 9 & 20 & - & - & - & 7 & - & - & - & - & - & - & 11 \\
\hline MP-TXH-091-A & - & - & - & - & - & 15 & 17 & - & - & 9 & 18 & - & - & 26 & - & - & - & 15 \\
\hline MP-TXH-092-A & - & - & - & 4 & - & 6 & 25 & - & - & - & 23 & - & - & 31 & - & - & - & 11 \\
\hline MT-HYM-028 & - & - & - & - & - & - & 11 & - & 38 & 1 & 23 & - & - & 20 & - & - & - & 7 \\
\hline MT-HYM-029 & - & - & - & - & - & 64 & 27 & 9 & - & - & - & - & - & - & - & - & - & - \\
\hline MT-HYM-030 & - & - & - & 9 & - & 39 & 27 & - & - & - & 18 & - & - & - & - & 2 & - & 5 \\
\hline MT-HYM-031 & - & - & - & - & - & - & 14 & - & 56 & - & 13 & - & - & - & - & - & - & 18 \\
\hline MT-HYM-032 & - & - & - & - & - & 27 & 29 & - & - & 30 & 1 & - & - & 12 & - & - & - & 1 \\
\hline MT-HYM-033 & - & - & - & - & - & - & 49 & 13 & - & 4 & 5 & - & - & 24 & - & 5 & - & - \\
\hline MP-TXH-075-A & - & - & - & - & - & 7 & 4 & 19 & - & - & 7 & - & 25 & 38 & - & - & - & - \\
\hline MP-TXH-118 & - & - & - & - & - & - & 12 & 44 & - & - & 5 & 24 & - & - & 13 & - & 2 & - \\
\hline МР-ТХН-119 & - & - & - & - & - & - & - & 25 & - & 42 & 17 & 10 & - & - & 7 & - & - & - \\
\hline MB-TXH-096-А & - & - & - & 14 & 26 & 15 & 10 & 1 & - & - & - & - & - & 34 & - & - & - & - \\
\hline MP-TXH-094-A & - & 24 & - & 10 & 8 & 12 & 28 & - & - & - & - & - & 13 & - & - & - & - & 6 \\
\hline MP-TXH-072-A & - & - & - & 46 & 14 & 5 & 17 & 3 & - & - & 9 & - & - & - & - & - & - & 5 \\
\hline MP-TXH-078-А & - & - & - & 26 & 14 & 18 & 18 & 6 & - & - & - & - & 10 & - & - & - & - & 8 \\
\hline MP-TXH-121 & - & - & - & - & - & 19 & 25 & 7 & - & - & 22 & - & 7 & - & - & - & - & 20 \\
\hline MP-TXH-054-A & - & - & - & 24 & - & 24 & 24 & 5 & - & - & 21 & - & - & - & - & 3 & - & - \\
\hline MP-TXH-070-A & - & - & - & - & - & - & 8 & 40 & - & - & 16 & - & - & 36 & - & - & - & - \\
\hline MP-TXH-097-A & 1 & - & - & - & - & 10 & 19 & - & - & - & 23 & - & - & - & 37 & - & - & 10 \\
\hline MP-TXH-067-A & - & - & - & 22 & - & 2 & 15 & - & 17 & - & 21 & - & - & 16 & - & - & - & 7 \\
\hline MP-TXH-082-A & - & - & - & - & - & - & 25 & - & - & 10 & 65 & - & - & - & - & - & - & - \\
\hline MP-TXH-083-A & - & - & - & - & - & 4 & 17 & - & - & - & 44 & - & - & - & 34 & - & - & 1 \\
\hline MP-TXH-085-A & - & - & - & - & - & - & 18 & - & - & 9 & 61 & - & - & 7 & - & - & - & 5 \\
\hline MP-TXH-093-A & - & - & - & - & - & - & 20 & - & - & 6 & 67 & - & - & - & - & - & - & 8 \\
\hline MP-TXH-069-A & - & - & - & - & - & - & 12 & - & - & - & 63 & - & - & 15 & - & - & - & 10 \\
\hline MB-TXH-068-D & - & - & - & - & - & 2 & 24 & - & - & 18 & 19 & - & - & 31 & - & - & - & 6 \\
\hline MP-TXH-073-A & - & - & - & 46 & 25 & 3 & 18 & 1 & - & - & - & - & - & - & - & - & - & 6 \\
\hline MP-TXH-098-A & - & - & - & - & - & - & 15 & 18 & - & - & 29 & - & 38 & - & - & - & - & - \\
\hline MP-TXH-099-А & - & - & - & - & - & - & 10 & 24 & - & - & 35 & - & 31 & - & - & - & - & - \\
\hline MP-TXH-125 & - & - & - & - & - & - & 20 & - & - & 13 & 58 & - & - & - & - & - & - & 9 \\
\hline МР-ТХH-126 & - & - & - & - & - & 7 & 19 & - & - & 6 & 48 & - & - & 6 & - & - & - & 14 \\
\hline TВ-TJM-127 & - & - & - & - & - & - & 42 & 22 & - & 11 & 12 & - & - & - & - & - & - & 13 \\
\hline
\end{tabular}

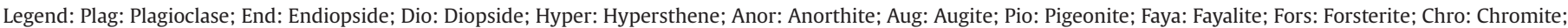
Enst: Enstatite; Hed: Hedenbergite; Bron: Bronzite; Troi: Troilite; Wolla: Wollastonite; Ilm: Ilmenite; Phos: Phosphates; Spi: Spinel.

abundance of plagioclase. One can also observe from the values listed in Table 5 that we have detected a similar percentage of anorthite only on the first sample (MB-TXH-071-A) as Lawrence and Lucey (2007).

Spectral mixing models are strongly dependent on the choice of reasonable end-member minerals. We have selected a larger number of end-member minerals to perform the spectral mixing than Lawrence and Lucey (2007). Besides the differences in the adopted fit models, this fact may explain part of the differences in the derived modal mineralogies. In addition, our modeled spectral curves of Y74450 (see Fig. 1) are a better representation of the absorption features of this meteorite, when compared to that obtained by Lawrence and Lucey (2007).

The results discussed in this section evidenced that the model described in Section 2 is able not only to provide globally satisfactory fits to HED meteoritic spectra but also mineralogical compositions which are generally in good agreement with results of other authors.

\subsection{Model performance on V-type asteroids}

We have performed an analysis to test the strength of our model solution. For this purpose, we have considered the fit of 

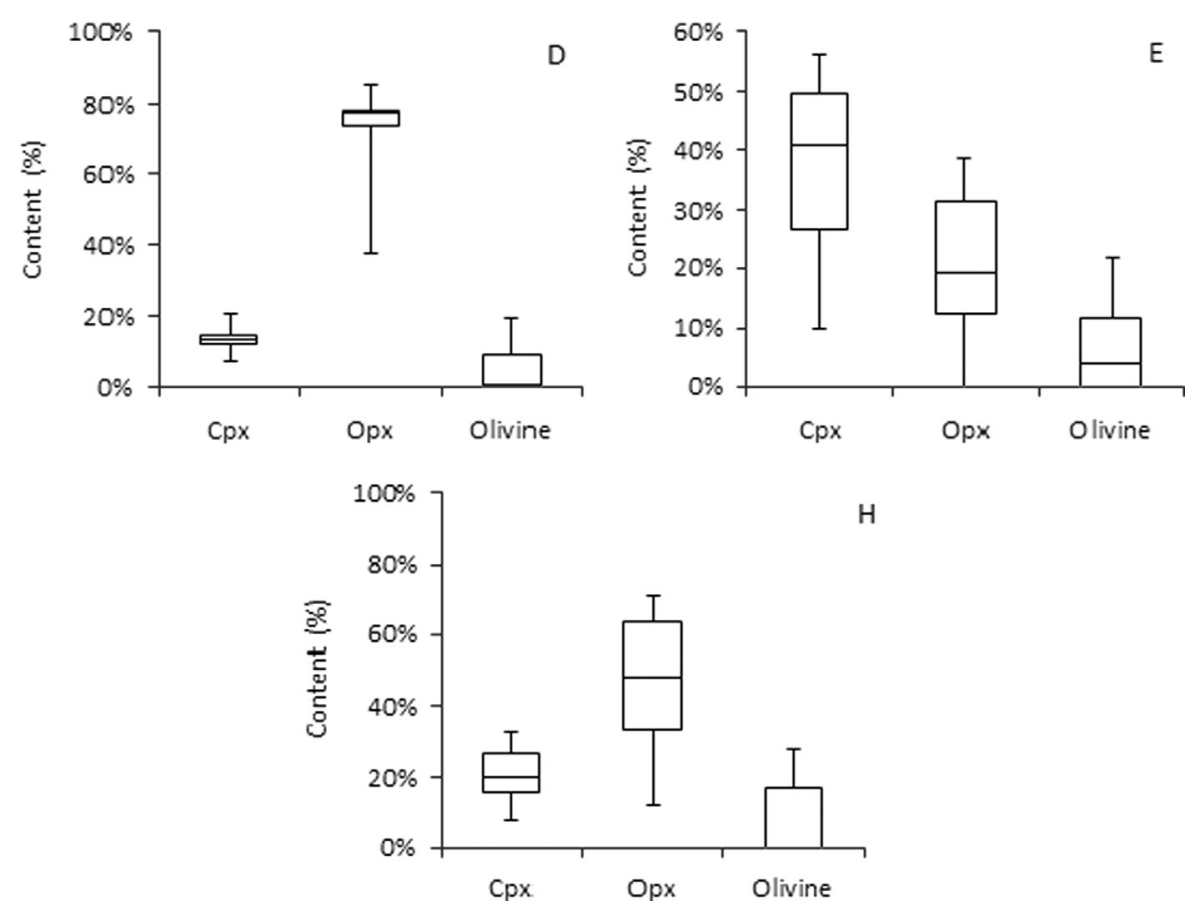

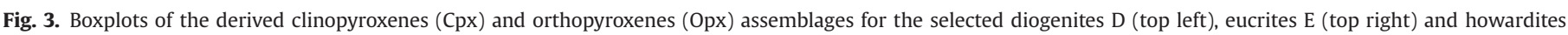
$\mathrm{H}$ (bottom), listed in Table 2.
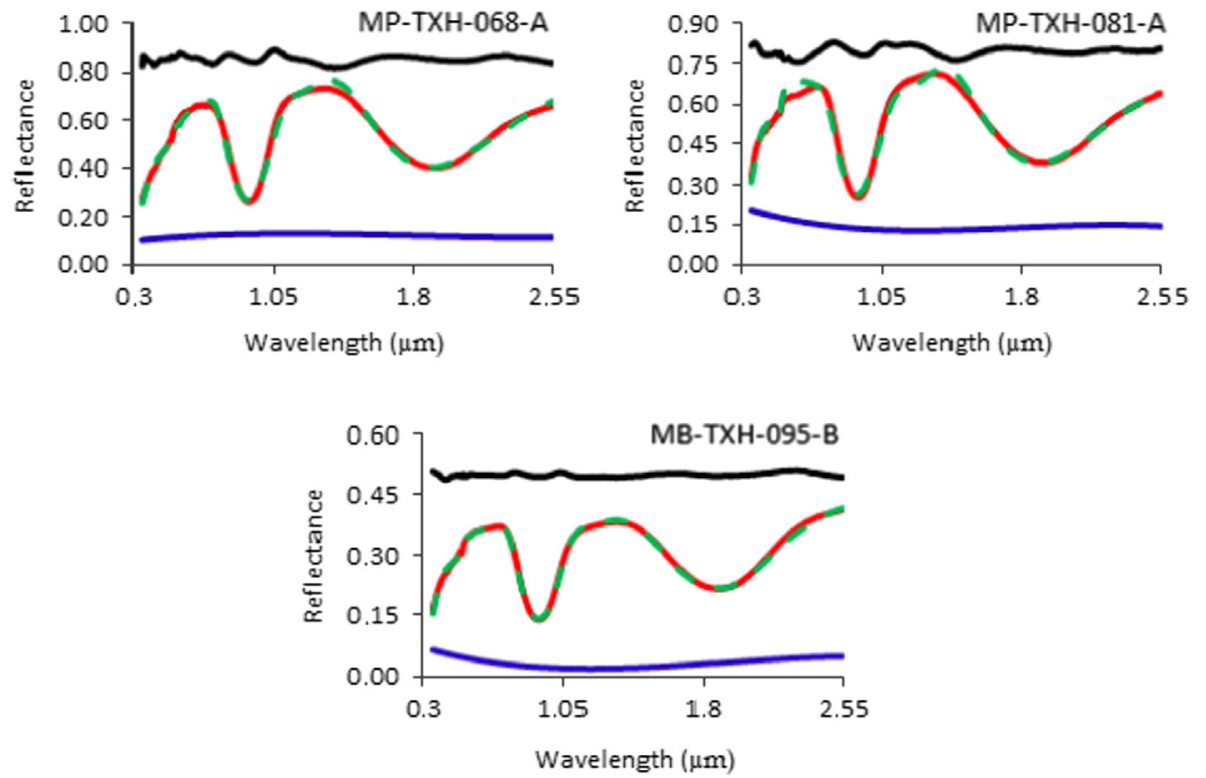

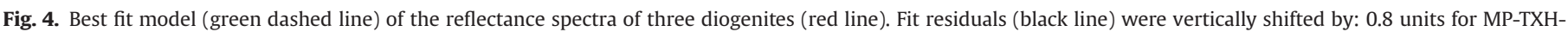

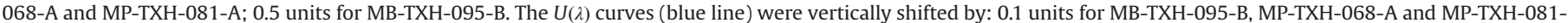

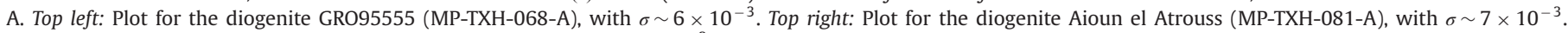

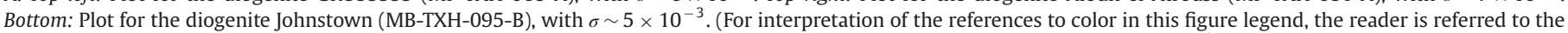
web version of this article.)

Table 8

Average inferred mineralogies of three diogenites. The values are listed in units of vol\%.

\begin{tabular}{|c|c|c|c|c|c|c|c|c|c|c|c|}
\hline Meteorite & Hyper & Anor & Pio & Faya & Chro & Enst & Bron & Troi & Ilm & Spi & $\sigma$ \\
\hline MP-TXH-068-А & - & - & 14 & 1 & - & 85 & - & - & - & - & $6.10^{-3}$ \\
\hline MP-TXH-081-A & - & - & 13 & - & 10 & 77 & - & - & - & - & $7.10^{-3}$ \\
\hline МB-ТХH-095-В & 12 & - & 13 & 10 & - & 37 & 28 & - & - & - & $5.10^{-3}$ \\
\hline
\end{tabular}

Legend: Hyper: Hypersthene; Anor: Anorthite; Pio: Pigeonite; Faya: Fayalite; Chro: Chromite; Enst: Enstatite; Bron: Bronzite; Troi: Troilite; Ilm: Ilmenite; Spi: Spinel. 
Table 9

Modeled surface mineralogies of asteroid (4) Vesta for the different cases (see text). The values are listed in order of decreasing $\sigma$, in units of vol\%.

\begin{tabular}{|c|c|c|c|c|c|c|c|c|c|c|c|c|c|c|}
\hline Case & End & Hyper & Anor & Aug & Pio & Faya & Chro & Enst & Hed & Bron & Troi & Ilm & Spi & $\sigma$ \\
\hline 11 & - & - & - & - & 20 & - & 2 & 4 & - & - & 74 & - & - & $1.8 \times 10^{-2}$ \\
\hline \multirow[t]{2}{*}{6} & - & - & - & 25 & - & 16 & 22 & 23 & - & - & - & - & 14 & $8.8 \times 10^{-3}$ \\
\hline & - & - & 58 & - & 27 & - & - & 15 & - & - & - & - & - & $7.5 \times 10^{-3}$ \\
\hline 2 & - & - & - & - & 15 & 6 & 3 & 39 & - & - & - & - & 38 & $7.3 \times 10^{-3}$ \\
\hline 9 & - & 27 & 14 & 5 & 19 & 1 & 19 & - & - & 6 & - & 10 & - & $3.6 \times 10^{-3}$ \\
\hline 8 & - & 25 & - & 3 & 16 & - & - & 10 & 5 & - & - & 4 & 36 & $3.3 \times 10^{-3}$ \\
\hline 10 & - & 40 & - & 5 & 15 & 2 & 9 & 2 & 3 & - & - & - & 25 & $3.1 \times 10^{-3}$ \\
\hline $3 / 4 / 7$ & - & 35 & - & 4 & 18 & - & 9 & - & 2 & 4 & - & 8 & 21 & $3.1 \times 10^{-3}$ \\
\hline 1 & 35 & - & - & - & 20 & - & 8 & - & - & 5 & - & 14 & 17 & $2.9 \times 10^{-3}$ \\
\hline
\end{tabular}

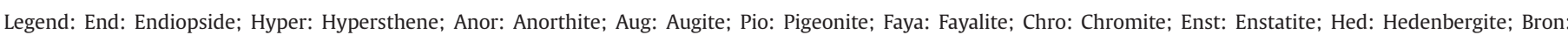
Bronzite; Troi: Troilite; Ilm: Ilmenite; Spi: Spinel.

(4) Vesta to investigate the impact on the model performance if we start to substract the presence of minerals from the fitting process. To test this scenario, we have considered the following cases in the fitting process: (1) absence of orthopyroxenes; (2) absence of clinopyroxenes; (3) absence of olivine; (4) absence of plagioclase; absence of all neutral phases; (6) absence of piogenite; (7) absence of enstatite; (8) absence of chromite; (9) absence of spinel; (10) absence of ilminite; (11) absence of the $U(\lambda)$ curve. The modeled surface mineralogies of (4) for these cases are listed in Table 9. From these results, one can observe the differences in the inferred mineralogies and how the model adapts itself for the different cases. Of key interest is to observe the importance of the presence of clinopyroxenes, piogenite, neutral phases and of the $U(\lambda)$ curve in the fitting process. The latter is evidenced by the goodness of the fits listed in Table 9. Indeed, these results are evidencing the presence of clinopyroxenes and neutral phases in the surface regolith of (4) Vesta. The method is based on a minimization procedure that tries to find the model parameters that give the best fit. Our efforts to ensure, as much as possible, global minimization allow us to consider that any results derived from the fittings depend, essentially, on the adopted model and not on the fitting process.

We have also applied the model described in Section 2 to the V-type asteroids listed in Table 1, for which we found a geometric albedo value in the literature. We list the inferred mineralogies and corresponding uncertainties, following the methodology adopted by Clark et al. (2006), in Table 10 and show the corresponding fits in Figs. 5-6. As one can observe from these figures, all modeled curves reproduce well the reflectance spectra of the asteroids. As expected, fit residuals show, in general, a flat behavior dominated by spectral noise. The exceptions is (137924) 2000 BD19, for which fit residuals show oscillations unrelated to spectral noise. For asteroids (4) Vesta, (52750) 1998 KK17 and (137924) 2000 BD19, the $U(\lambda)$ polynomials are increasing monotonous, which may be indicative of spectral reddening produced by space weathering effects on these asteroids (Clark et al., 2002). In the other cases, this cannot be ascertained because the $U(\lambda)$ polynomials show a nonmonotonous variation with wavelength.

In order to test the performance of the mixing model in V-type asteroids, we compare our inferred modal abundances with the literature (e.g., Lawrence and Lucey, 2007; Donaldson and Sprague, 2009). It is also worth to mention that the modeled surface composition of (4) Vesta is consistent with an eucritic-tohowarditic composition (see the mineralogical distributions of orthopyroxenes and clinopyroxenes for eucrites, shown in Fig. 3). The latter is also in agreement with the results from the Dawn mission (e.g., de Sanctis et al., 2013).

Lawrence and Lucey (2007) performed a mixing spectral analysis of (4) Vesta and inferred the following surface mineralogy: $38.0 \%$ of orthopyroxenes, $27.6 \%$ of clinopyroxenes, $41.0 \%$ of anorthite and $1.0 \%$ of troilite. Our analysis of (4) Vesta is based on a reflectance spectrum obtained at $39^{\circ} \mathrm{W}$ longitude. Our inferred orthopyroxenes and clinopyroxenes contents agree with the one of Lawrence and Lucey (2007). On the other hand, we have not detected the presence of anorthite as in Lawrence and Lucey (2007). Instead, we have found a high percentage of neutral phases, such as ilminite, chromite and spinel. Our modeled spectral curve of (4) Vesta (see Fig. 5) seems to better reproduce its absorption feature located at $1.9 \mu \mathrm{m}$, than the one obtained by Lawrence and Lucey (2007).

Donaldson and Sprague (2009) derived the mineralogy of (4) Vesta using a spectral deconvolution algorithm. Their fit to the MIDAS ${ }^{2}$ spectrum (see Donaldson and Sprague, 2009 for mode details, with reference to Lim et al. (2005)), obtained at $73-96^{\circ} \mathrm{W}$ longitude, showed that this region of (4) Vesta surface is composed by $55-65 \%$ of pyroxenes (varying from pigeonite to hypersthene and augite) and $15-25 \%$ of plagioclase and minor amounts of olivine and chromite. Our inferred modal percentage of pyroxenes are within the range presented by Donaldson and Sprague (2009), but we have inferred a higher modal abundance of neutral phases and we have also not detected the presence of plagioclase. On the other hand, their fit to the $\mathrm{ISO}^{3}$ spectrum (see Donaldson and Sprague, 2009 for mode details, with reference to Dotto et al. (2000)), obtained at $221^{\circ} \mathrm{W}$ longitude, evidenced that this region of (4) Vesta surface is composed by 49-59\% of pyroxenes (varying from pigeonite to augite and hypersthene), $13-23 \%$ of plagioclase, $15-25 \%$ of olivine and minor amounts of diopside and quartz. The percentage of pyroxenes found in this fit seems to be in better agreement with the percentage that we have derived, for (4) Vesta. However, we have not detected the presence of plagioclase and olivine.

The improved $\sigma$ of the fits, as compared with previous studies, is a sign that space weathering and other usually unaccounted effects, as discussed here, play an important role in spectral fits.

\subsection{On the quest of the genetic relationship between HED meteorites and V-type asteroids}

The genetic relationship between HED meteorites and V-type asteroids has long been discussed in the literature across the years (see e.g., McCord et al., 1970; Binzel and Xu, 1993; Binzel et al., 1997, 2002; Drake, 2001; Burbine et al., 2002). Despite the recent results from the Dawn mission that strengthened this linkage (see e.g., de Sanctis et al. 2012, 2013; McSween et al. 2011, 2013),

\footnotetext{
${ }^{2}$ MIDAS is an acronym for Mid Infrared Asteroids Spectroscopic Survey (Lim et al., 2005).

${ }^{3}$ ISO is an acronym for Infrared Space Observatory (Dotto et al., 2000).
} 
Table 10

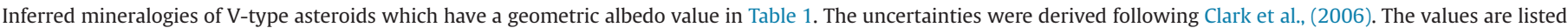
in units of vol\%.

\begin{tabular}{|c|c|c|c|c|c|c|c|c|c|c|c|c|c|c|c|c|c|}
\hline Asteroid Name & Plag & Hyper & Anor & Aug & Pio & Faya & Fors & Chro & Enst & Hed & Bron & Troi & Wolla & Ilm & Phos & Spi & $\sigma$ \\
\hline (4) Vesta & - & $35_{0}^{+1}$ & - & 4 & $18_{-1}^{+1}$ & - & - & $9_{-1}^{0}$ & - & 2 & $4_{0}^{+1}$ & - & - & $8_{-1}^{+1}$ & - & $21_{-1}^{+1}$ & $3.1 \times 10^{-3}$ \\
\hline (854) Frostia & - & - & - & 8 & $21_{-2}^{+1}$ & $9_{-1}^{0}$ & - & $34_{-2}^{+1}$ & $5_{-1}^{0}$ & $22_{-1}^{+1}$ & $0_{0}^{+2}$ & - & - & - & - & $1_{-1}^{+1}$ & $1.0 \times 10^{-3}$ \\
\hline (3908) Nyx & - & - & - & $22_{-1}^{+1}$ & $7^{-2}$ & - & $29_{-2}^{+2}$ & $24_{-1}^{+1}$ & $19_{-1}^{+1}$ & - & - & - & - & - & - & - & $8.4 \times 10^{-3}$ \\
\hline (4055) Magellan & - & - & - & 5 & $22_{-1}^{+1}$ & - & $38_{-2}^{+2}$ & $21_{-1}^{+1}$ & $14^{-1}$ & - & - & - & - & - & - & - & $7.4 \times 10^{-3}$ \\
\hline (5604) $1992 \mathrm{FE}$ & $3_{-2}^{+2}$ & - & - & 21 & $26_{-1}^{+1}$ & - & - & $11^{-1}$ & $39_{-1}^{+1}$ & - & - & - & - & - & - & - & $1.1 \times 10^{-2}$ \\
\hline (6611) 1993 VW & - & 1 & - & 4 & $24_{-1}^{+1}$ & 1 & $36_{-2}^{+2}$ & 10 & $9^{-1}$ & - & - & - & - & - & 13 & 2 & $3.2 \times 10^{-3}$ \\
\hline (21238) Panarea & - & - & - & - & $12^{-1}$ & - & - & - & $14_{-1}^{+1}$ & - & - & - & 65 & 9 & - & - & $8.7 \times 10^{-3}$ \\
\hline (52750) 1998 KK17 & - & 18 & 7 & - & $22_{-1}^{+1}$ & - & $29_{-2}^{+2}$ & 15 & 2 & 8 & - & - & - & - & - & - & $7.7 \times 10^{-3}$ \\
\hline (137924) 2000 BD19 & - & $6_{-2}^{+2}$ & - & - & $11_{-1}^{+1}$ & - & - & $48_{-1}^{+1}$ & - & 36 & - & - & - & - & - & - & $5.6 \times 10^{-3}$ \\
\hline
\end{tabular}

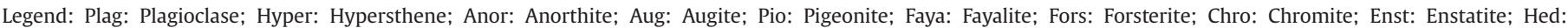
Hedenbergite; Bron: Bronzite; Troi: Troilite; Wolla: Wollastonite; Ilm: Ilmenite; Phos: Phosphates; Spi: Spinel.
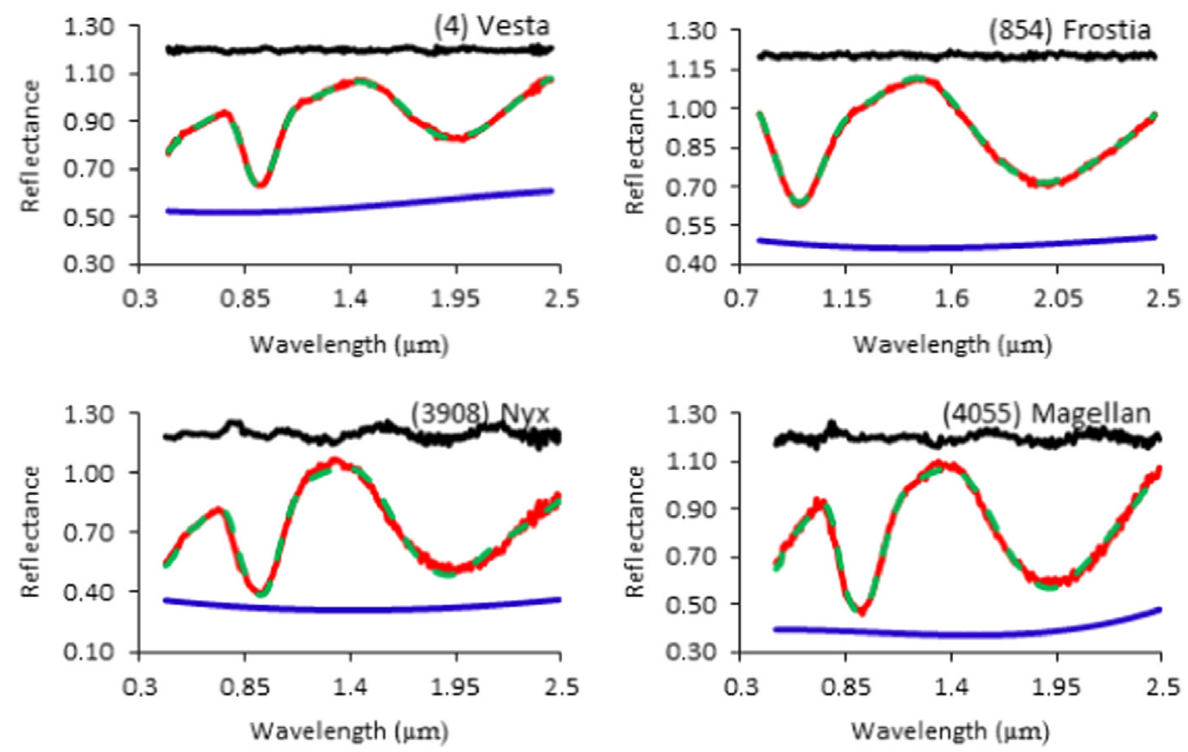

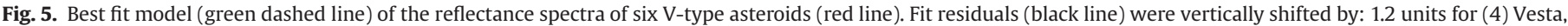

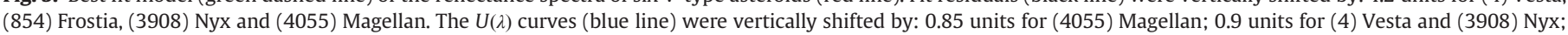

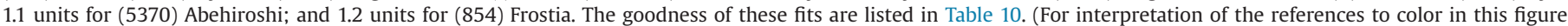
legend, the reader is referred to the web version of this article.)

it is still questioned by some authors (see, e.g., Schiller et al., 2011; Wasson, 2013). We also aim to analyze this genetic linkage.

We first tried to identify possible meteoritic analogues of the selected V-type asteroids, by gathering a set of HED meteorite spectra that closely matched. We have performed a $\chi^{2}$ test to find the best spectral matches for each of the asteroids listed in Table 10. We list the results of this test in Table 11. In Fig. 7, we show the best spectral match found for each asteroid. We do not show the result for (137924) 2000 BD19, as the $\chi^{2}$ for the first best spectral match is too high. Based on these results, we have identified that (4) Vesta, (3908) Nyx, (4055) Magellan, (5604) $1992 \mathrm{FE}$ and (6611) $1993 \mathrm{VW}$ seem to have a similar mineralogy to howardites. On the other hand, we have identified that (854) Frostia and (52750) 1998 KK17 seem to have a mineralogy similar to eucrites. (21238) Panarea appears to have a mineralogy similar to a diogenite, which is in good agreement with the result pointed out by de Sanctis et al. (2011a). We have not included asteroids (286458) 2005 VW and 2003 FT3 in this analysis since we have not found their geometric albedo value in the literature.

In Fig. 8, we show a plot of clinopyroxenes versus orthopyroxenes abundances, for all the V-type asteroids listed in Table 1 which have a geometric albedo value listed. The derived mass fractions indicate that the surface of V-type asteroids and the selected HED meteorites are composed by a mixture of pyroxenes. Some traces of olivine were also found in some HED meteorites. These results strengthen the relationship between (4) Vesta, Vestoids and HED meteorites (McCord et al., 1970), as also evidenced by recent results from the DAWN mission (de Sanctis et al. 2012, 2013; McSween et al. 2011, 2013). According to our fit results for (4) Vesta and also to its position in Fig. 8, (4) Vesta's mineralogy is composed by eucritic-tohowarditic material, as also evidenced by the results from the DAWN mission (de Sanctis et al. 2013).

According to Fig. 8, (4) Vesta, (3908) Nyx, (4055) Magellan, (5604) 1992 FE and (6611) 1993 VW agree with eucritic-tohowarditic mineralogies. This evidence also confirms the linkages previously established through the $\chi^{2}$ test and also shown in Fig. 7 , between these five asteroids and their howardite analogues. Also, according to Burbine et al. (2009), the mineralogy of (3908) Nyx is probably similar to one of an eucrite or howardite, which is in good agreement with our results. (854) Frostia is located in the vicinity of the dynamical family of (4) Vesta. But, Zappala et al. (1995) has not included this asteroid as a member of the family of (4) Vesta. In fact, not all the objects in the vicinity of (4) Vesta belong to its family (Duffard et al., 2004). The best spectral match identified for (854) Frostia was an eucrite. Indeed, its pyroxene mineralogy is similar to the ones of eucrites (Fig. 8), but is found 

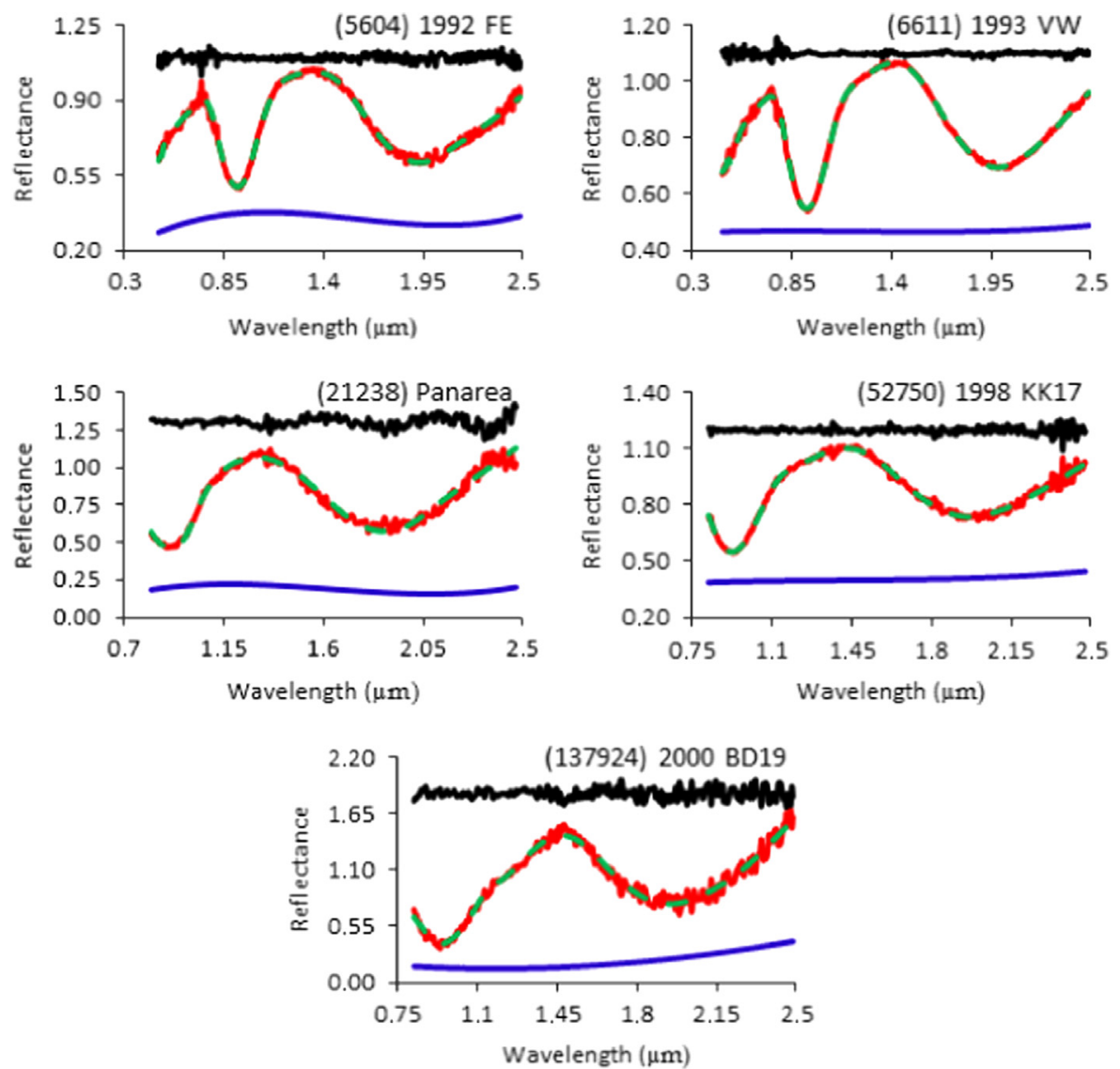

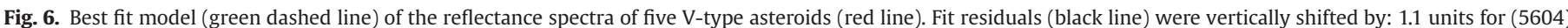

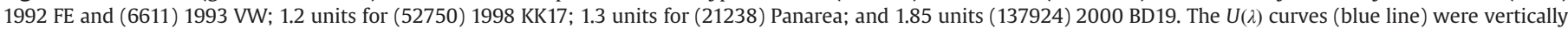

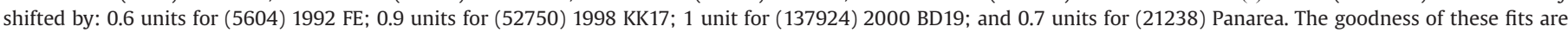
listed in Table 10. (For interpretation of the references to color in this figure legend, the reader is referred to the web version of this article.)

Table 11

The three best spectral matches (BSM) for the V-type asteroids listed in Table 10. The $\chi^{2}$ value of each BSM is specified in parenthesis.

\begin{tabular}{|c|c|c|c|}
\hline Asteroid Name & BSM 1 & BSM 2 & BSM 3 \\
\hline (4) Vesta & Howardite MP-TXH-053-A (0.21) & Eucrite MP-TXH-089-A (0.88) & Eucrite MP-TXH-078-A (0.94) \\
\hline (854) Frostia & Eucrite MP-TXH-119 (0.61) & Eucrite MT-HYM-030 (0.75) & Howardite MP-TXH-067-A (0.80) \\
\hline (3908) Nyx & Howardite MP-TXH-126 (1.02) & Diogenite MP-TXH-071-A (1.08) & Howardite MP-TXH-082-A (1.59) \\
\hline (4055) Magellan & Howardite MP-TXH-093-A (0.65) & Howardite MP-TXH-097-A (1.24) & Howardite MP-TXH-126 (1.36) \\
\hline (5604) $1992 \mathrm{FE}$ & Howardite MP-TXH-093-A (0.55) & Howardite MP-TXH-126 (1.00) & Howardite MP-TXH-099-A (1.09) \\
\hline (6611) $1993 \mathrm{VW}$ & Howardite MP-TXH-073-A (0.40) & Howardite MP-TXH-067-A (0.52) & Eucrite MP-TXH-096-A (0.54) \\
\hline (21238) Panarea & Diogenite MB-TXH-095-B (0.61) & Diogenite MP-TXH-088-A (0.73) & Diogenite MP-TXH-068-A (0.73) \\
\hline (52750) 1998 KK17 & Eucrite MP-TXH-072-A (0.34) & Eucrite MP-TXH-119 (0.38) & Eucrite MP-TXH-121 (0.41) \\
\hline (137924) 2000 BD19 & Eucrite MT-HYM-033 (10.40) & Eucrite MP-TXH-054-A (10.70) & Eucrite MP-TXH-087-A (10.80) \\
\hline
\end{tabular}

close to the border of the $2 \sigma$ region of eucrites. Despite we have not identified a meteoritic analogue for (137924) 2000 BD19 among the selected HED meteorites, this asteroid has similar pyroxene mineralogical composition similar to eucrites (Fig. 8). On the other hand, (21238) Panarea does not have a pyroxene mineralogy consistent with any HED type (Fig. 8). Actually, de Sanctis et al. (2011b) also quote that this asteroid has spectral parameters which differ from V-type asteroids in the inner belt and argue that it may be not related to (4) Vesta.

Indeed, our results not only contradict the conclusions of Schiller et al. (2011) and Wasson (2013), but also evidence that not all HED meteorites may come from (4) Vesta. There are also other V-type asteroids in the vicinity of the dynamical family of (4) Vesta that may also be plausible parent bodies of HED meteorites, as is the example of (854) Frostia. However, we do not discard the possibility that HED meteorites may also come from asteroids other than the V-type asteroids.

The collisions suffered by (4) Vesta, eventually ejected a big amount of material into its neighborhood. Some of the ejected fragments agglomerated and originated small bodies, which show a howarditic-type spectra (i.e., composed by eucritic and diogenitic material-see Fig. 8). These bodies would have formed the family of howarditic-type asteroids. In this scenario, (3908) Nyx, (4055) Magellan, (5604) 1992 FE and (6611) 1993 VW may be a result of the agglomeration of eucritic and diogenitc material after the collision suffered by (4) Vesta. On the other hand, eucritic material is quoted to have been originated from the mantle close to (4) Vesta surface (Takeda, 1997). As we linked (52750) 1998 KK17 to an eucrite, this asteroid was probably formed in the uppermost layers of (4) Vesta. Diogenitic material is postulated to 


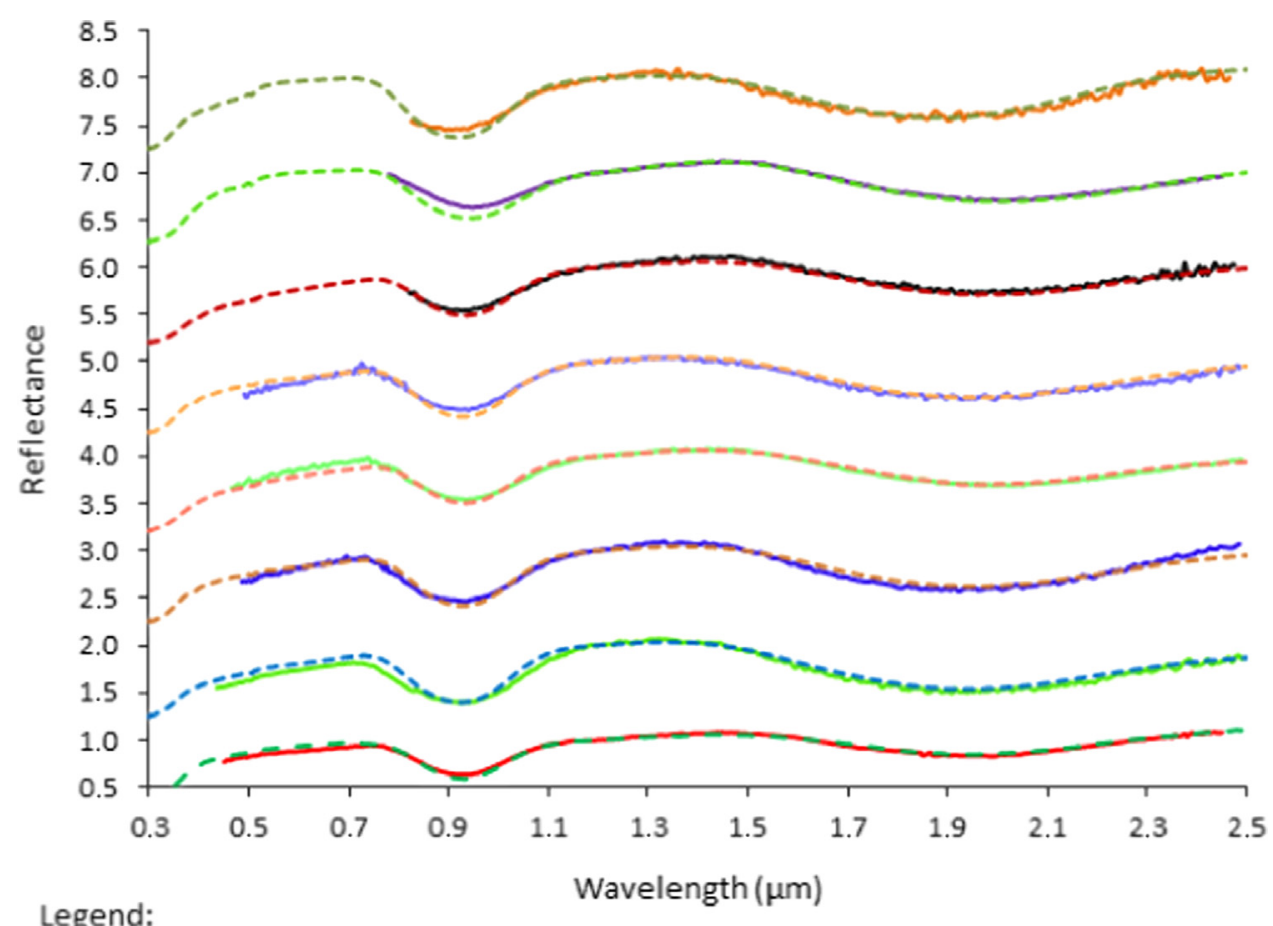

Legend:

Wavelength $(\mu \mathrm{m})$

\begin{tabular}{|c|c|}
\hline (4) Vesta & - - - Howardite MP-TXH-053-A \\
\hline$-(3908) \mathrm{Nyx}$ & ---Howardite MP-TXH-126 \\
\hline - (4055) Mage llan & -----Howardite MP-TXH-093-A \\
\hline - (6611) 1993 VW & ----- Howardite MP-TXH-073-A \\
\hline -(5604) $1992 \mathrm{FE}$ & ----Howardite MP-TXH-093-A \\
\hline (52750) 1998 KK17 & ---Eucrite MP-TXH-072-A \\
\hline -(854) Frostia & ---Eucrite MP-TXH-119 \\
\hline -(21238) Panarea & - - - Diogenite M B-TXH-095-B \\
\hline
\end{tabular}

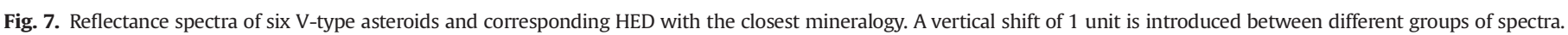

be present in the innermost layers of (4) Vesta (Takeda, 1997). If the collisions suffered by (4) Vesta reached the inner layers close to the mantle, some traces of olivine might also be found in some Vestoids and HED meteorites. Actually, as evidenced by our inferred mineralogies, we have found a considerable content of olivine in almost all of the selected V-type asteroids (see Table 10) and several HED meteorites (see Table 7). Of particular interest is the amount of olivine inferred for (6611) $1993 \mathrm{VW}$, which is in agreement with the indication pointed out by Duffard et al. (2006). Such evidence may favor the magma ocean model of (4) Vesta interior (Righter and Drake, 1997).

The silicate mineralogy inferred for the studied V-type nearEarth asteroids requires that their parent body suffered early igneous differentiation in its history, producing a basaltic surface lithology (Sunshine et al., 2004). Indeed, the presence of Opx in asteroids can be considered as a tracer of their igneous history. Minerals like Opx and plagioclases were preferentially incorporated in early partial melts from a chondritic precursor and depleted in residues of partial melting (Sunshine et al., 2004). So, (4) Vesta is indeed a differentiated asteroid.

\section{Conclusions}

This implementation of the bidirectional Hapke radiative transfer model (Hapke, 1993) is well adapted to infer the mineralogy of V-type asteroids and HED meteorites. We have performed modal analysis on laboratorial samples, HED meteorites and V-type asteroids. The model provides globally satisfactory fits. The mineralogical compositions that we have inferred for Opx and Cpx are in good agreement with results of other authors. The advantage of using this method is that it is possible to choose a high number of reasonable end-members minerals for the modeling process and derive their respective modal abundances.

We have inferred average mineralogical compositions for eucrites ( $21 \pm 3 \%$ of Opx, $40 \pm 4 \%$ of Cpx, $10 \pm 3 \%$ of olivine, $7 \pm 2 \%$ of chromite, $11 \pm 3 \%$ of troilite, $6 \pm 1 \%$ of spinel and $3 \pm 1 \%$ of plagioclase), howardites ( $47 \pm 7 \%$ of Opx, $25 \pm 4 \%$ of Cpx, $8 \pm 3 \%$ of olivine, $5 \pm 2 \%$ of chromite, $7 \pm 3 \%$ of troilite and $6 \pm 1 \%$ of spinel) and diogenites ( $73 \pm 10 \%$ of $\mathrm{Opx}, 13 \pm 2 \%$ of $\mathrm{Cpx}, 5 \pm 1 \%$ of olivine, $5 \pm 2 \%$ of chromite, $2 \pm 2 \%$ of troilite and $2 \pm 1 \%$ of spinel) suitable for comparison with future mineralogical studies of these objects. 

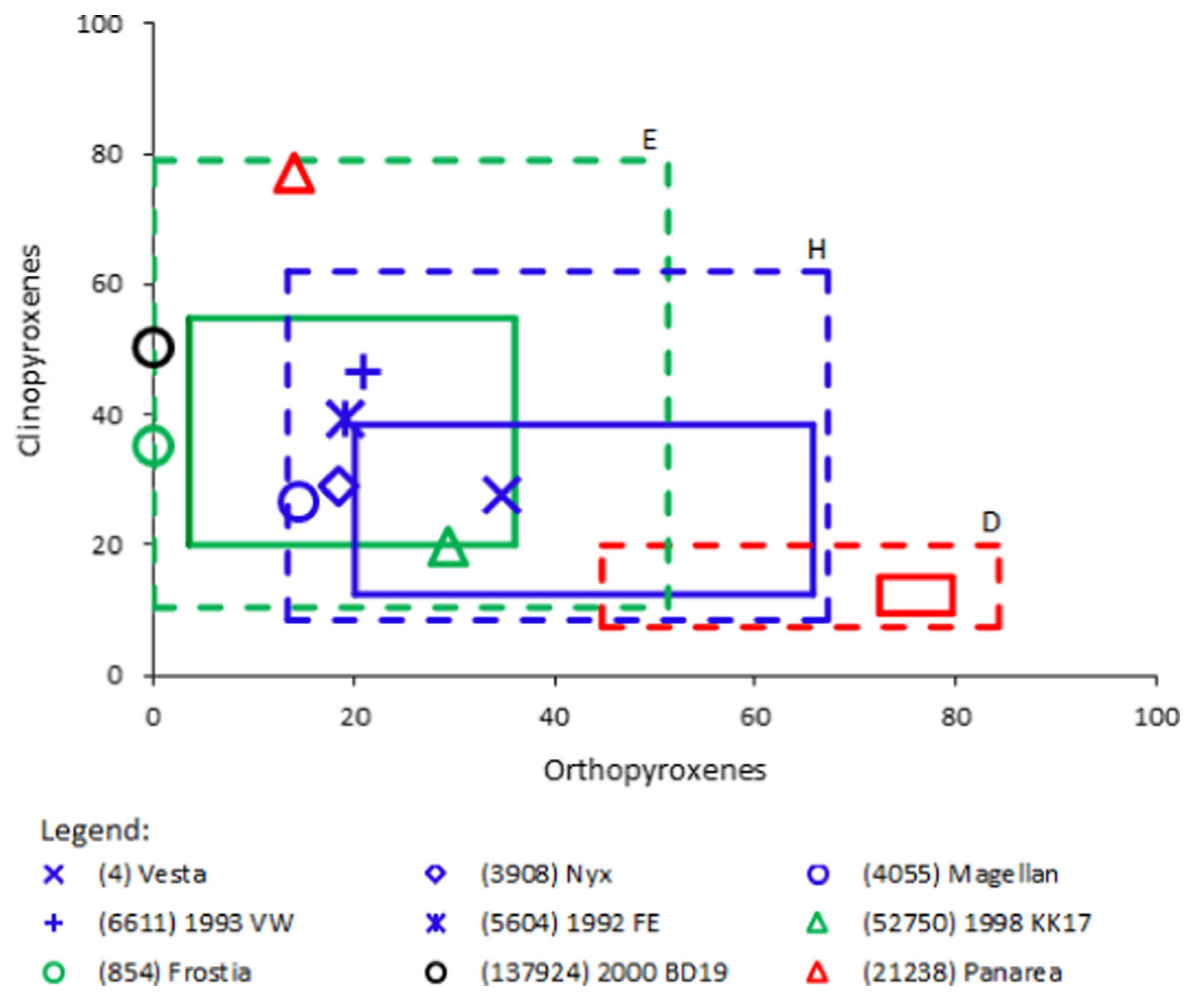

Fig. 8. Plot of the clinopyroxenes content vs orthopyroxenes content for the eleven V-type asteroids. The colored solid rectangles define the $1 \sigma$ (or 1 standard deviation from the average) region of the statistical mineralogical distributions of Cpx and Opx, while the dashed colored rectangles define the $2 \sigma$ (or 2 standard deviations from the average) region. The statistical mineralogical distribution of: eucrites is represented by green rectangles, howardites by blue rectangles and diogenites by red rectangles. The asteroids bullets are highlighted in red, blue or green according to their meteoritic analogue type previously indentified. For the asteroids highlighted with a black bullet, no meteoritic analogue was found. The values are listed in units of vol\%. (For interpretation of the references to color in this figure legend, the reader is referred to the web version of this article.)

Our results not only contradict the evidence pointed out by Schiller et al. (2011) and Wasson (2013), but also agree with results from the Dawn mission that strengthened the linkage between (4) Vesta and HED meteorites (de Sanctis et al. 2012, 2013; McSween et al. 2011, 2013). However, we do not discard the possibility that HED meteorites may also come from other asteroids of different types. We have identified some V-type asteroids in the close vicinity of the (4) Vesta family, such as (854) Frostia, that can also be a plausible HED parent body. Our results emphasize that some of the studied near-Earth Vestoids may come from different layers of (4) Vesta, as suggested by Takeda (1997). We have confirmed that (4) Vesta, (3908) Nyx, (4055) Magellan, (5604) 1992 FE and (6611) 1993 VW have mineralogies consistent with howardites. On the other hand, we have found that (52750) 1998 KK17 and (854) Frostia have mineralogies consistent with eucrites. Also, according to our results, (21238) Panarea is also confirmed to have not a pyroxene mineralogy similar to HED meteorites and (4) Vesta.

The mineralogical analysis of the V-type asteroids evidenced that these are mainly composed by pyroxenes. We have also found a considerable content of olivine in several of the selected V-type asteroids, which can favor the magma ocean model of (4) Vesta interior (Righter and Drake, 1997).

\section{Acknowledgements}

Most of the data used in this publication were obtained and made available by the The MIT-UH-IRTF Joint Campaign for NEO Reconnaissance. The IRTF is operated by the University of Hawaii under Cooperative Agreement no. NCC 5-538 with the National Aeronautics and Space Administration, Office of Space Science, Planetary Astronomy Program. The MIT component of this work is supported by NASA grant 09-NEOO009-0001, and previously by the National Science Foundation under Grant no. 0506716. The authors would like to thank all researchers who collaborated in the RELAB and The MIT-UH-IRTF Joint Campaign for NEO Spectral Reconnaissance, who generously made their work publically available for further studies. We are also thankful to both referees, for their detailed revisions and helpful comments that much improved this paper.

\section{References}

Ammannito, E., de Sanctis, M.C., Capaccioni, F., Teresa Capria, M., Carraro, F., Combe, J.-P., Fonte, S., Frigeri, A., Joy, S.P., Longobardo, A., Magni, G. Marchi, S., McCord, T.B., McFadden, L.A., McSween, H.Y., Palomba, E., Pieters, C.M., Polanskey, C.A., Raymond, C.A., Sunshine, J.M., Tosi, F., Zambon, F., Russell, C.T., 2013. Vestan lithologies mapped by the visual and infrared spectrometer on Dawn. Meteorit. Planet. Sci. 48 (11), 2185-2198.

Binzel, R.P., Xu, S., 1993. Chips off of asteroid 4 Vesta: evidence for the parent body of basaltic achondrite meteorites. Science 260, 186-191.

Binzel, R.P., Gaffey, M.J., Thomas, P.C., Zellner, B.H., Storrs, A.D., Wells, E.N., 1997. Geologic mapping of Vesta from 1994 hubble space telescope images. Icarus 128 (1), 95-103.

Binzel, R.P., Lupishko, D., di Martino, M., Whiteley, R.J., Hahn, G.J., 2001. Physical properties of near-Earth objects. In: Bottke Jr., W.F., Cellino, A., Paolicchi, P., Binzel, R.P. (Eds.), Asteroids III. University of Arizona Press, Tucson, AZ pp. $255-271$.

Bowman, L.E., Spilde, M.N., Papike, J.J., 1997. Automated EDS modal analysis as applied to the diogenites. Meteorit. Planet. Sci. 32, 869-875.

Burbine, T.H., McCoy, T.J., Meibom, A., Gladman, B., Keil, K., 2002. Meteoritic parent bodies: their number and identification. In: Bottke Jr., W.F., Cellino, A., Paolicchi, P., Binzel, R.P. (Eds.), Asteroids III. University of Arizona Press, Tucson, AZ, pp. 653-667.

Burbine, T.H., Buchanan, P.C., Dolkar, T., Binzel, R.P., 2009. Pyroxene mineralogies of near-Earth vestoids. Meteorit. Planet. Sci. 44 (9), 1331-1341.

Burns, R.G., 1970. Crystal field spectra and evidence of cation ordering in olivine minerals. Am. Mineral. 55, 1608-1632.

Burns, R.G., 1993. Mineralogical Applications of Crystal Field Theory, second ed. Cambridge University Press, Cambridge p. 551. 
Clark, B.E., Hapke, B., Pieters, C., Britt, D., 2002. Asteroid space weathering and regolith evolution. In: Bottke Jr., W.F., Cellino, A., Paolicchi, P., Binzel, R.P. (Eds.), Asteroids III, Eds. University of Arizona Press, Tucson, AZ, pp. 585-599.

Clark, B., Bus, S., Rivkin, A., McConnochie, T., Sanders, J., Shah, S., Hiroi, T., Shepard, M., 2006. E-type asteroid spectroscopy and compositional modeling. J. Geophys. Res. 109 (E2), E02201.

Cloutis, E.A., Gaffey, M.J., 1992. Pyroxene spectroscopy revisited: spectralcompositional correlations and relationship to geothermometry. J. Geophys. Res. 96, 22809-22826.

de Sanctis, M.C., Migliorini, A., Luzia Jasmin, F., Lazzaro, D., Filacchione, G., Marchi, S., Ammannito, E., Capria, M.T., 2011a. Spectral and mineralogical characterization of inner main-belt V-type asteroids. Astron. Astrophys. 533 (A77), 10.

de Sanctis, M.C., Ammannito, E., Migliorini, A., Lazzaro, D., Capria, M.T., McFadden, L., 2011b. Mineralogical characterization of some V-type asteroids, in support of the NASA Dawn mission. Mon. Not. R. Astron. Soc. 412 (4), 2318-2332.

de Sanctis, M.C., Ammannito, E., Capria, M.T., Tosi, F., Capaccioni, F., Zambon, F., Carraro, F., Fonte, S., Frigeri, A., Jaumann, R., Magni, G., Marchi, S., McCord, T.B. McFadden, L.A., McSween, H.Y., Mittlefehldt, D.W., Nathues, A., Palomba, E., Pieters, C.M., Raymond, C.A., Russell, C.T., Toplis, M.J., Turrini, D., 2012. Spectroscopic characterization of mineralogy and its diversity across Vesta. Science 336 (6082) (697-690).

de Sanctis, M.C., Ammannito, E., Capria, M.T., Capaccioni, F., Combe, J.-P., Frigeri, A. Longobardo, A., Magni, G., Marchi, S., McCord, T.B., Palomba, E., Tosi, F., Zambon, F., Carraro, F., Fonte, S., Li, Y.J., McFadden, L.A., Mittlefehldt, D.W., Pieters, C.M., Jaumann, R., Stephan, K., Raymond, C.A., Russell, C.T., 2013. Vesta's mineralogical composition as revealed by the visible and infrared spectrometer on Dawn. Meteorit. Planet. Sci. 48 (11), 2166-2184.

Dotto, E., Müller, T.G., Barucci, M.A., Encrenaz, T., Knacke, R.F., Lellouch, E., Doressoundiram, A., Crovisier, J., Brucato, J.R., Colangeli, L., Mennella, V., 2000. ISO results on bright Main Belt asteroids: PHT-S observations. Astron. Astrophys. 358, 1133-1141.

Donaldson Hanna, K., Sprague, A.L., 2009. Vesta and the HED meteorites: midinfrared modeling of minerals and their abundances. Meteorit. Planet. Sci. 44 (11) , 1755-1770.

Drake, M.J., 2001. The eucrite-Vesta story. Meteorit. Planet. Sci. 36 (4), 501-513.

Duffard, R., Lazzaro, D., Licandro, J., de Sanctis, M.C., Capria, M.T., Carvano, J.M. 2004. Mineralogical characterization of some basaltic asteroids in the neighborhood of (4) Vesta: first results. Icarus, 171; , pp. 120-132.

Duffard, R., de Léon, J., Licandro, J., Lazzaro, D., Serra-Ricart, M., 2006. Basaltic asteroids in the near-Earth objects population: a mineralogical analysis. Astron. Astrophys. 456, 775-781.

Hapke, B., 1993. Theory of Reflectance and Emittance Spectroscopy, first ed. Cambridge University Press, New York.

Hiroi, T., Binzel, R.P., Sunshine, J.M., Pieters, C.M., Takeda, H., 1995. Grain sizes and mineral compositions of surface regoliths of Vesta-like asteroids. Icarus 115, 374-386.

Klima, R.L., Pieters, C.M., Dyar, M.D., 2007. Spectroscopy of synthetic Mg-Fe pyroxenes I: spin-allowed and spin-forbidden crystal field bands in the visible and near-infrared. Meteorit. Planet. Sci. 42, 235-253.

Lawrence, S.J., Lucey, G., 2007. Radiative transfer mixing models of meteoritic assemblages. J. Geophys. Res. 112, E07005.

Lim, L.F., McConnochie, T.H., Bell III, J.F., Hayward, T.L., 2005. Thermal infrared $(8-13 \mu \mathrm{m})$ spectra of 29 asteroids: the Cornell mid-infrared asteroid spectroscopy (MIDAS) survey. Icarus 173, 385-408.

Lucey, P., 1998. Model near-infrared optical constants of olivines and pyroxene as a function of iron content. J. Geophys. Res. 103, 1703-1713.
McCord, T.B., Adams, J.B., Johnson, T.V., 1970. Asteroid Vesta: spectral reflectivity and compositional implications. Science 168 (3938), 1445-1447.

McSween, H.Y., Mittlefehldt, D.W., Beck, A.W., Mayne, R.G., McCoy, T.J., 2011. HED meteorites and their relationship to the geology of Vesta and the dawn mission. Space Sci. Rev. 163 (1-4), 141-174.

McSween, H.Y., Binzel, R.P., de Sanctis, M.C., Ammannito, E., Prettyman, T.H., Beck, A.W., Reddy, V., Corre, L., Gaffey, M.J., McCord, T.B., Raymond, C.A., Russell, C.T., 2013. Dawn; the Vesta-HED connection; and the geologic context for eucrites, diogenites, and howardites. Meteorit. Planet. Sci. 48 (11), 2090-2104.

Morimoto, N., Fabries, J., Ferguson, A.K., Ginzburg, I.V., Ross, M., Seifeit, F.A., Zussman, J., 1989. Nomenclature of pyroxenes. Can. Mineral. 27, 143-156.

Mustard, J.F., Pieters, C.M., 1989. Photometric phase functions of common geologic materials and applications to quantitative analysis of mineral mixture reflectance spectra. J. Geophys. Res. 94 (13), 619-634.

Nelson, M.L., Britt, D.T., Lebofsky, L., 1993. Mineralogy of asteroids compositions. Resour. Near-Earth Space, 493-522.

Papike, J.J., Shearer, C.K., Spilde, M.N., Karner, J.M., 2000. Metamorphic diogenite Grosvenor Mountains 95555: mineral chemistry of orthopyroxene and spinel and comparisons to the diogenite suite. Meteorit. Planet. Sci. 35 (4), 875-879.

Pieters, C.M., Hiroi, T., 2004. RELAB (Reflectance Experiment Laboratory): A NASA Multi-user Spectroscopy Facility. LPS, 35, Abstract \#1720 (CDROM).

Rayner, J.T., Tooney, D.W., Onaka, P.M., Denault, A.J., Stahlberger, W.E., Vacca, W.D., Cushing, M.C. Wang, S., 2003. SpeX: a medium-resolution 0.8-5.5 $\mu \mathrm{m}$ spectrograph and imager for the NASA infrared telescope facility. Publ. Astron. Soc. Pac. 115 (805), 362-382.

Righter, K., Drake, M.J., 1997. A magma ocean on Vesta: core formation and petrogenesis of eucrites and diogenites. Meteorit. Planet. Sci. 32, 929-944.

Russell, C.T., Raymond, C.A., Coradini, A., McSween, H.Y., Zuber, M.T., Nathues, A., De Sanctis, M.C., Jaumann, R., Konopliv, A.S., Preusker, F., Asmar, S.W., Park, R.S., Gaskell, R., Keller, H.U., Mottola, S., Roatsch, T., Scully, J.E.C., Smith, D.E., Tricarico, P., Toplis, M.J., Christensen, U.R., Feldman, W.C., Lawrence, D.J., McCoy, T.J., Prettyman, T.H., Reedy, R.C., Sykes, M.E., Titus, T.N., 2012. Dawn at Vesta: testing the protoplanetary paradigm. Science 336, 684-686.

Schiller, M.J., Baker, J., Creech, J., Paton, C., Millet, M.-A., Bizzaro, M., 2011. Rapid timescales for magma ocean crystallization on the howardite-eucrite-diogenite parent body. Astrophys. J. 740, L22.

Sunshine, J., Pieters, C., Pratt, S., 1990. Deconvolution of mineral absoprtion bands: an improved approach. J. Geophys. Res. 95, 6955-6966.

Sunshine, J.M., Bus, S.J., McCoy, T.J., Burbine, T.H., Corrigan, C.M., Binzel, R.P., 2004. Hgh-calcium pyroxene as an indicator of igneous differentiation in asteroids and meteorites, Meteorit. Planet. Sci. 39 (8), 1343-1357.

Takeda, H., 1997. Mineralogical records of early planetary process on the HED parent body with reference to Vesta. Meteorit. Planet. Sci. 32, 834-853.

Wasson, J.T., Wetherill, G.W., 1979. Dynamical Chemical and Isotopic Evidence Regarding the Formation Locations of Asteroids and Meteorites. In: Asteroids. (A80-24551 08-91) Tucson, AZ, University of Arizona Press, 926-974.

Wasson, J.T., 2013. Vesta and extensively melted asteroids: why HED meteorites are probably not from Vesta. Earth Planet. Sci. Lett. 381, 138-146.

Zappala, V., Bendjoya, P., Cellino, A., Farinella, P., Froeschle, C., 1995. Asteroid families: search of a 12487 asteroid sample using two different clustering techniques. Icarus 116, 291-314.

Zema, M., Domeneghetti, M.C., Molin, G.M., Tazzoli, V., 1997. Cooling rates of diogenites: a study of $\mathrm{Fe} 2+-\mathrm{Mg}$ ordering in orthopyroxene by X-ray singlecrystal diffraction. Meteorit. Planet. Sci. 32, 855-862. 